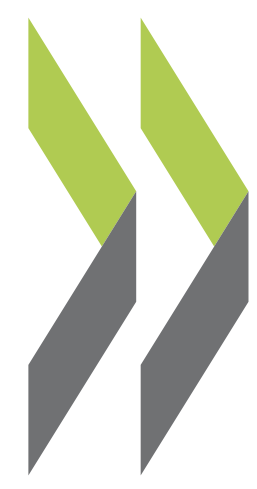

OECD Science, Technology and Industry Working Papers 2018/03

\title{
Industrial robotics \\ and the global organisation of production
}

\section{Koen De Backer,}

\section{Timothy DeStefano,}

Carlo Menon,

Jung Ran Suh 


\section{OECD SCIENCE, TECHNOLOGY AND INDUSTRY WORKING PAPERS}

The release of this working paper has been authorised by Andrew Wyckoff, OECD Director for Science, Technology and Innovation and by Luiz De Mello, OECD Director for the Economics Department.

OECD Working Papers should not be reported as representing the official views of the OECD or of its member countries. The opinions expressed and arguments employed are those of the authors. Working Papers describe preliminary results or research in progress by the author(s) and are published to stimulate discussion on a broad range of issues on which the OECD works. Comments on Working Papers are welcomed, and may be sent to Directorate for Science, Technology and Innovation, OECD, 2 rue André-Pascal, 75775 Paris Cedex 16, France.

This document, as well as any data and any map included herein, are without prejudice to the status of or sovereignty over any territory, to the delimitation of international frontiers and boundaries and to the name of any territory, city or area.

This publication is a contribution to the OECD Going Digital project, which aims to provide policymakers with the tools they need to help their economies and societies prosper in an increasingly digital and data-driven world.

For more information, visit www.oecd.org/going-digital

\#GoingDigital

(C) OECD 2018

You can copy, download or print OECD content for your own use, and you can include excerpts from OECD publications, databases and multimedia products in your own documents, presentations, blogs, websites and teaching materials, provided that suitable acknowledgment of OECD as source and copyright owner is given. All requests for commercial use and translation rights should be submitted to rights@oecd.org. 


\title{
INDUSTRIAL ROBOTICS AND THE GLOBAL ORGANISATION OF PRODUCTION
}

Koen DE BACKER, Timothy DESTEFANO, Carlo MENON and Jung RAN SUH.

\begin{abstract}
Increased robot use, fuelled by price declines and the increased dexterity of these machines, is expected to affect existing/future production technologies and the organisation of production within GVCs. In order to safeguard their competitiveness in an increasingly digitalised global economy, governments across OECD and emerging economies are implementing a range of policy measures/programmes to support the investment in and use of robotics. This paper assesses the extent to which robotics impact the organisation of production through offshoring and backshoring. The results indicate that the use of industrial robots in developed economies appears to be slowing the offshoring rates, although it is not yet prompting firms to bring jobs back home. However, the effect is very recent, especially in labour-intensive sectors, and not yet apparent in developing countries. The findings suggest the rate of global value chain expansion may be slower than in the past.
\end{abstract}




\section{TABLE OF CONTENTS}

ABSTRACT 3

INDUSTRIAL ROBOTICS AND THE GLOBAL ORGANISATION OF PRODUCTION 6

1. Introduction 6

2. Robotisation in manufacturing $\quad 10$

$\begin{array}{ll}2.1 \text { The rise of robots } & 10\end{array}$

2.2 Robots across countries and industries 12

3. Robotics and the location of production $\quad 17$

3.1. Robotics and offshoring $\quad 17$

3.2. Robotics and reshoring 18

3.3. Robotics and the reallocation of resources within MNEs 20

4. Robotics and GVC integration and upgrading $\quad 22$

5. Policy aspects on robotics, GVCs and competitiveness 28

5.1. Government policies on robotics investment and usage 28

5.2 Conclusion and policy implications $\quad 32$

NOTES

REFERENCES 38

ANNEX A: EMPIRICAL STRATEGIES AND VARIABLE DESCRIPTIONS 42

A1.1. Robot stock and offshoring $\quad 42$

A1.2. Robot stock and backshoring $\quad 42$

A1.3. Robot stock and reallocation $\quad 43$

A1.4. Robot stock, GVC upgrading, comparative advantage and participation 43

ANNEX B 


\section{Tables}

Table 1. $\quad$ Effects of growth in robotics on the growth of offshoring 18

Table 2. $\quad$ Effects of growth in robotics on backshoring within MNEs 20

Table 3. Effects of growth in robotics on the reallocation of resources within MNEs 21

Table 4. Effects of growth in robotics on GVC upgrading 24

Table 5. Effects of growth in robotics on comparative advantage $\quad 25$

Table 6. Effects of growth in robotics on backward participation 26

Table 7. Effects of growth in robotics on forward participation 27

Table B.1. $\quad$ Effects of growth in robotics on imports over demand 44

\section{Figures}

Figure 1. The confluence of key technologies enabling the industrial digital transformation $\quad 7$

Figure 2. Annual patent applications for specific manufacturing technologies $\quad 10$

Figure 3. Robot stock amongst top 10 using economies, 2000 to $2016 \quad 12$

Figure 4. The price of robots, ICT and non-ICT capital (1998=100) 13

Figure 5. Robot intensity amongst top 25 using economies, $2016 \quad 14$

Figure 6. Robot purchases by sector amongst highest users, $2016 \quad 15$

Figure 7. Industrial robot sales by application, $2016 \quad 16$

Figure 8. The volume of robots produced in Korea $\quad 29$

Figure 9. Value of robots produced in Korea by category $\quad 29$

\section{Boxes}

Box 1. Speedfactory Adidas $\quad 9$

Box 2. Data on robotics 13

Box 3. Robots policy and industry in Korea $\quad 28$ 


\section{INDUSTRIAL ROBOTICS AND THE GLOBAL ORGANISATION OF PRODUCTION}

\section{Introduction}

What was once confined to science fiction, the rapid proliferation of industrial robotics is well on its way to becoming science fact. Today robots are increasingly prominent in manufacturing industries with parts of - and in some cases, complete - production processes automated. Programmable and repetitive activities such as welding, painting, picking and placing are nowadays done by industrial robots in a growing number of industries. The robotisation of manufacturing first took off in OECD economies as it helped to compensate for high and rising labour costs and safeguard international competitiveness. Indeed, robots were already used widely in auto manufacturing in the 1980s? but growth in computing and other information and communication technologies has made possible a sharp pick-up in recent years and robot use is spreading to far more industries.. In recent years, strong robotics investment can also be observed in several emerging economies $^{1,}$ often supported by their governments, as part of their industrialisation and development strategies. New robot technology has profound implications for the organisation of production, trade and jobs because of its capacity to adapt and learn and to carry out tasks requiring fine motor skills; tasks once confined to humans or machines with extensive human intervention.

The growing trend of robotisation is expected to continue in the future, and the general expectation is that industrial robots will become more pervasive over the coming decades. The Boston Consulting Group suggests that a real robotics revolution is about to take place with many manufacturing industries reaching an inflection point at which robotisation will become commercially viable. As a rule of thumb, BCG estimates that automation is pursued when using robots becomes $15 \%$ cheaper than employing humans. In some industries, more than $40 \%$ of manufacturing tasks are expected to be done by robots (BCG, 2015). Alongside industrial robots is the growing use of computer automated applications, which are also expected to complement and substitute human labour from now into the future (Frey and Osborne, 2017). Growing robotisation is therefore part of the broader trend of the digitalisation of manufacturing, with new digital technologies expected to radically change the outlook of industries. In light of the opportunities and challenges created by digitalisation, companies will (need to) organise their domestic and global production processes differently and adopt new business models.

OECD (2017a) has distinguished three broad technological developments underpinning the digitalisation of production; the Internet of Things (IoT) - which enables the interconnection of machines, inventories and goods; big data and embedded software, which allow for the analysis of the huge volumes of digital data generated by these objects; and cloud computing, which is providing ubiquitous availability of computing power (Figure 1). The uptake and growth of (industrial) robots or autonomous machines within sectors will result from the conjunction of these different technologies and applications. While costs of hardware and enabling software are expected to fall further, the performance of robotics systems will vastly improve. BCG (2015) estimates that the cost of robots will decrease by $20 \%$ and their performance improve by around $5 \%$ annually over the next decade. Robots which are already widely used across manufacturing industries are rather suited for repetitive activities and very precisely defined environments. While some robots are equipped with on-board 
INDUSTRIAL ROBOTICS AND THE GLOBAL ORGANISATION OF PRODUCTION sensors, most of their movements are pre-planned and programmed. Machines will however become more flexible due to the progress of artificial intelligence, self-learning and auto-correcting capabilities, allowing them to perform a wider range of complex activities. Machines will be increasingly able to do many tasks more precisely, cheaper and faster.

Figure 1. The confluence of key technologies enabling the industrial digital transformation

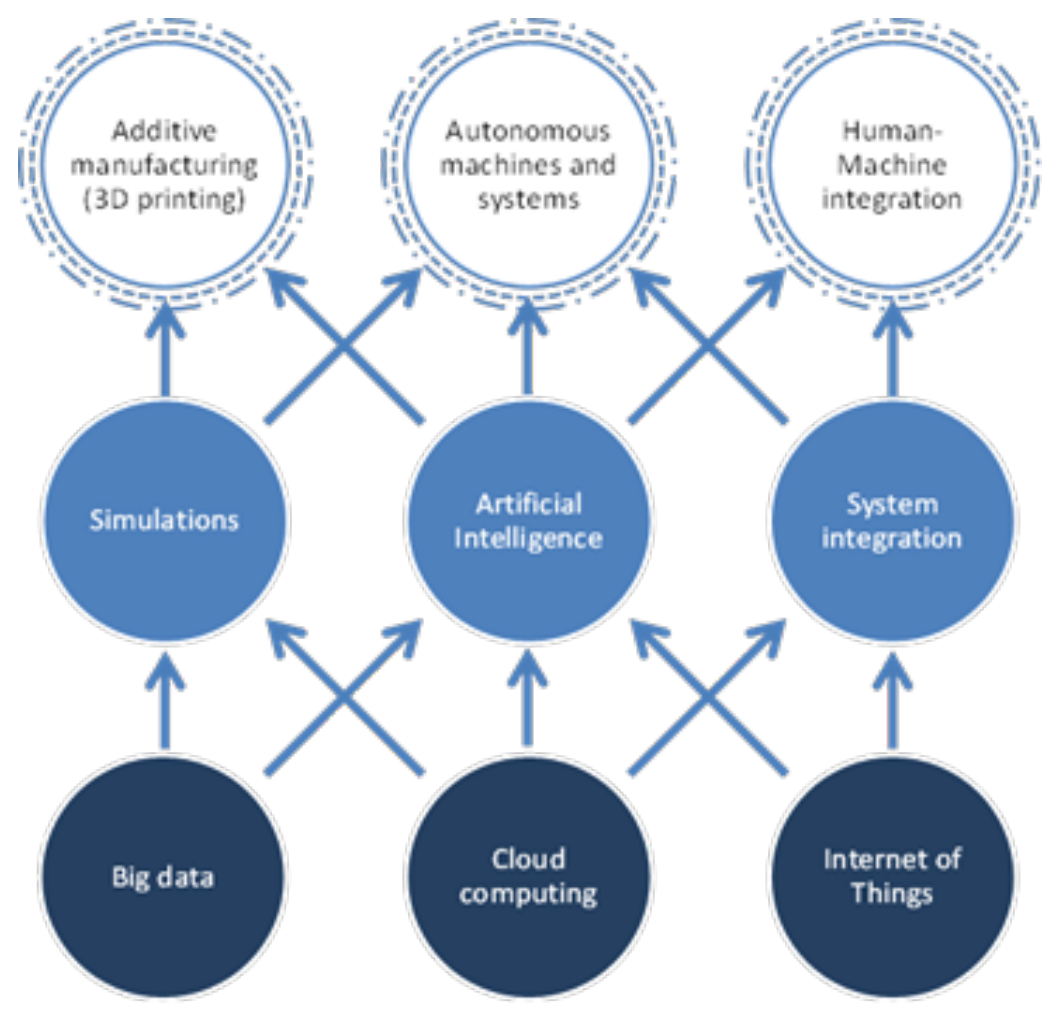

Source: OECD (2017a)

The rising prominence of robotics - and the digital (r)evolution more broadly - is increasingly attracting the attention of policy makers because of its possible effects on national economies. While high on the policy agenda in OECD economies, the impacts of new digital technologies are uncertain and not well understood in general. The OECD has already addressed a number of issues in recent work, and will continue to do so in the PWB 2017-18 within the horizontal project on “Going Digital - Making the Transformation work for Growth and Wellbeing”. This paper on robotics and the location of production aims to contribute to this broader OECD project.

Up until now, only limited empirical and policy evidence exists on the economic and social importance of robotics use. Recently, the discussion around robotics has centred particularly on the implications of labour markets - especially in developed economies - as robots are expected to have a major impact on employment. There is a widespread concern that new technologies might destroy a large number of jobs and cause “technological unemployment”. Robots are now capable of replacing a host of routine tasks performed within the firm and as their capabilities improve their ability to carry out non-routine tasks will increase. Some economists believe that many of the tasks and jobs today will be undertaken by robots in the coming years (Brynjolfsson and McAfee, 2011; Ford, 2009). Widely cited work by Frey and Osborne (2017) suggest that potentially 47\% of US employment may be threatened by computerisation and automation in the future. Comparable exercises have produced similar results for other countries, all pointing to a significant to large impact of robots and automation. However, other research expects that that the effects of robots on employment may be 
significantly smaller (see for example OECD, 2016a). Indeed, the literature has produced mixed results until now. For example, Graetz and Michaels (2015) find only marginal effects on hours worked, while Acemoglu and Restrepo (2017) do find a negative impact of robots on employment and wages. As for the types of jobs thought to be the most at risk to industrial robots and automation, these include blue collar jobs and routine occupations, while the groups of employees who are most at risk of wage decline or job lose are low-skilled males (Graetz and Michaels, 2015; Acemoglu and Restrepo, 2017; and Frey and Osborne, 2017).

In addition to potential employment effects, some empirical work has analysed the effect of robotics on (labour) productivity. Michael and Graetz (2015) report, for a panel of 17 countries over the period 1993-2007, a positive impact of robots on labour productivity, as well as total factor productivity - and thus economic growth. In discussing the future of robots, also BCG (2015) expects a strong rise of productivity as a result of the wider adoption or robotics in manufacturing. Further OECD work within the cross-cutting project on "Going Digital" will also focus on the links between digitalisation, robots and productivity.

But the potential effects of robots on national economies go further than employment and productivity effects. Increased robot use, fuelled by the continuous decline in the price of robots and the increased dexterity of machines, is expected to affect existing and future production technologies and the organisation of production within GVCs. In economic terms, robots can be considered as a close substitute for lower-skilled labour and a complement to higher-skilled labour ${ }^{2}$. Significant investments in robotics will alter relative factor endowments and thus factor costs in countries and this will/may change the location of production. For example, iRobotics produces a robot called Baxter that can understand and carry out a range of routine assembly line tasks. Baxter costs USD 22000 and has an average lifespan of 3 years (roughly 6500 working hours), which equates to a wage of roughly USD 3.38 an hour (Larson, 2013; Miller, 2013). Increased automation and robotics will overall decrease the importance of labour costs in total production costs, hence making the (re-) location of productive activities in OECD economies (again) more attractive. This is exacerbated by the decreasing gap in hourly wages between emerging and developed economies and robots continuing to become more economical. Differences in the cost of production between developed and emerging markets may thus narrow further, encouraging firms to restructure their global activities (Alix Partners, 2017; De Backer and Flaig, 2017).

Another important reason why robots may affect the location of production and change the international fragmentation of production and GVCs in the future is due to their ability to enhance the flexibility of the production process. Robots may not only make it more cost effective to produce products at home, but also allow firms to satisfy consumer demand by raising quality and enabling greater customisation of goods. The current organisation of production in long and complex GVCs has made companies less responsive to changes in customer demand, while at the same time product customisation is becoming essential for firms to maintain a competitive edge. Some have argued that a shift from mass production to mass customisation is happening, hence the need for companies to be able to quickly respond to market signals. Autonomous machines will increasingly allow for producing smaller batches of a wider variety at a lower cost.

As such, it could be hypothesised that robotics will impact the existing patterns of offshoring and may also lead to the reshoring of activities back to OECD economies (De Backer et al., 2016; Dachs and Zanker, 2015) ${ }^{3}$. Greater efficiency of robots and at lower costs is making it more cost effective in some cases for firms to move production back or close to the home country. This may be particularly pertinent for firms in developed countries, who previously offshored jobs to developing countries to benefit from lower labour costs (Lewis 2014; UNCTAD 2016). While mostly anecdotal, there are a host of examples of botsourcing (i.e. firms replacing humans with robots by building new factories in the home country, which are based on highly automated production plans) including Philips and Parkdale (Clifford, 2013; Markoff, 2012). Adidas recently opened a shoe 
INDUSTRIAL ROBOTICS AND THE GLOBAL ORGANISATION OF PRODUCTION factory in Germany called a Speedfactory with the objective of getting new shoe designs to consumers faster (Box 1).

\section{Box 1. Speedfactory Adidas}

Following the decision of one of the company's major competitors, Nike, to produce shoes through a robotised system in the United States, the world-known German sport footwear company Adidas decided to adopt a similar strategy by bringing production back from Asia to Germany. The first robotised plant was opened in Ansbach in Southern Germany, while the company also plans to establish a Speedfactory in the United States in 2017. Together, both factories are expected to produce a minimum of 1 million pairs of shoes every year. About 160 new jobs are expected to be created at the German plant, mostly highly-skilled labour to maintain the robots. Bringing production back from the People's Republic of China (hereafter "China") and Viet Nam will help the company to offset long shipping times but also the rising cost of labour in some Asian countries. More importantly, it will also help Adidas to meet the demand for rapid innovation in designs and styles. Based on the current supply chain model, the average industry time for shoes to reach consumers (from design to delivery) takes 18 months (unless transported by plane). Within a Speedfactory, however, the use of robots and $3 \mathrm{D}$ printers enables shoe components to be produced and assembled in-house, reducing the expected delivery time (from virtual design to a store shelf) to less than a week (Economist, 2017).

Advances in information technology were the catalyst for fragmentation of production across countries from the late 1980s that drive the large expansion of GVCs subsequently but this may be going into reverse. In discussing the future of GVCs, De Backer and Flaig (2017) demonstrated that digital technologies may again act as the biggest game changer for GVCs but in the opposite direction, with domestic sourcing becoming (again) more attractive relative to offshoring and a rebalancing of the global economy towards OECD economies. In addition, the localisation of production - i.e. bringing production closer to markets - is expected to become increasingly important within GVCs in the future. While De Backer and Flaig (2017) modelled different trajectories in productivity across countries to mimic the future adoption of digital technologies, this paper uses historical data (up to 2014) on robot investments across industries and countries, to deepen the analysis and to study the specific effects of robots on the location of production within GVCs. ${ }^{4}$ One drawback of this approach is that the robotics revolution is (only) in the beginning stages and that the potential impacts may not be observed yet. The fact that this paper reports now already on a number of effects, albeit small, may be an indication of the large impact robots will generate in the future. 


\section{Robotisation in manufacturing}

\subsection{The rise of robots}

Sales of global industrial robots ${ }^{5}$ rose to 294000 units in 2016, with an additional 1.4 million units forecast to be purchased between 2016 and 2019 (IFR, 2017; IFR, 2016). In the next three years the operational stock of industrial robots is forecasted to reach 2.6 million machines. The increase in global use of robots has also sparked an investment boom where global venture capital investment in robotics doubled between 2014 and 2015 to reach USD 587 million (Waters and Bradshaw, 2016). Simultaneously, innovation in automation hardware and software has led to a considerable increase in robot patent filings amongst the largest robotics producers (Figure 2). The current trend of global investment coupled with increasing innovation in robotics and complementary manufacturing technologies suggests that automated machines will continue to become more advanced and prevalent in the coming years. Given the complementarities between these technologies, it is not surprising that innovation amongst these tools is increasing simultaneously. By the year 2025, most production processes could be almost entirely autonomous (OECD, 2017b).

Figure 2. Annual patent applications for specific advanced manufacturing technologies

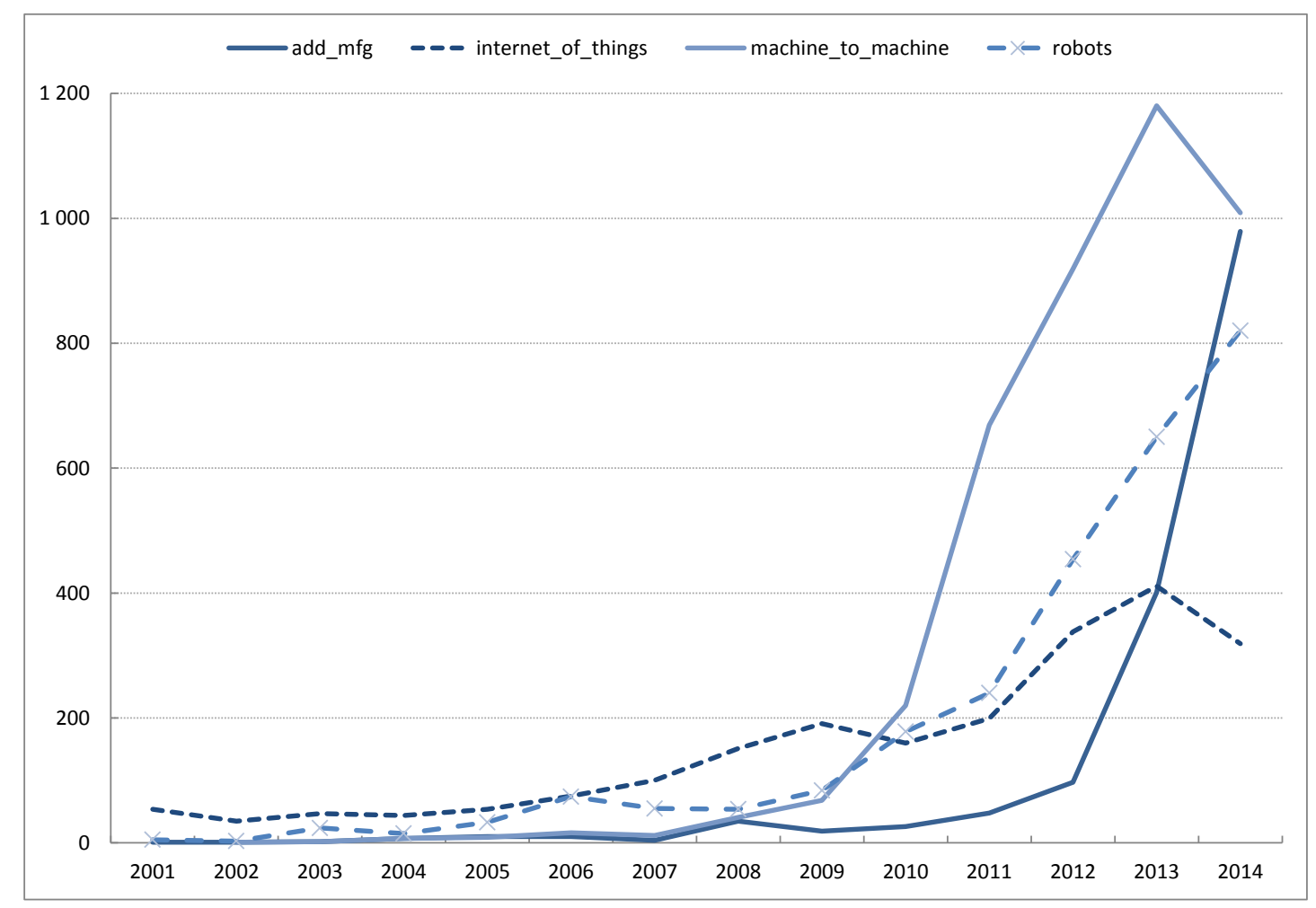

Note: Data on patent applications come from the US Patent Office and the European Patent Office so the figures may have a somewhat downward bias since the data exclude patents filed at the Korean and Japanese Patent Offices.

Source: Calculations based on PATSTAT.

In the past, robots were predominantly used in manufacturing to carry out tasks that required considerable labour input and that were dangerous for humans to do. For example, the first industrial robot used in a New Jersey General Motors plant was the Unimate which sequenced and stacked diecast metals at high temperatures (IFR, 2012). As robot capabilities quickly increased, they were used for routine tasks which required speed, agility and dexterity such as spot welding, stacking, 
INDUSTRIAL ROBOTICS AND THE GLOBAL ORGANISATION OF PRODUCTION drilling, cutting and so on. Today, automated machines increasingly incorporate sensors and machine learning that increase the type of tasks that can be undertaken (OECD, 2015). Robots can therefore be employed for a growing number of activities within firms including, transporting goods, quality assessment, the testing of products, and so on (PWC, 2014). Tesla is currently installing robot systems to produce the Model S automobile, which are expected to be so complex and efficient that people will not directly operate the machines or even work in the production line (Feng, 2016).

One of the main reasons why firms are adopting robots is their performance in terms of productivity and thus output. Robots typically can work continuously and carry out functions 24 hours a day. For example, within the mining industry a number of firms are beginning to rely on driverless trucks and drills in mines enabling continuous output (Simonite, 2016). In addition, there are a number of examples in which robots considerably reduce the time it takes to carry out an activity within the production line. Painting robots used by Boeing reduced the time it took a team to paint the wing of a Boeing 777 from 4.5 hours to 24 minutes (Gates, 2013). Furthermore a recent empirical paper by Graetz and Michaels (2015) find evidence that robot adoption results in greater output, value added and total factor productivity.

In addition, the use of robots during the production process improves the quality of parts and products, while at the same time reducing the need for quality inspection staff (Argote and Goodman, 1985). The introduction of vision-guided robots for example is believed to increase accuracy and precision in a number of areas, particularly when tasks are not repeatable, when the industrial environment is less than ideal, and when quality is crucial, such as food production to ensure the quality of raw food (Agapakis et al., 1990 and Gunasekaran, 1996). One of the most intensive users of robots, the automotive industry, relies on robots to monitor quality through a host of production processes such as defaults in body panels, uneven paint finishes, breaks in adhesive sealants, irregular welding beads, all of which are found to increase the quality of the end product (Bogue, 2013).

Incorporating robots within the production process can also influence the variety of goods that firms produce. For example, robots are thought to enable firms to make adjustments - more efficiently - on the manufacturing floor, switching from producing a vintage product to a new good, and thus enhancing the product mix (Argote and Goodman, 1985). This helps businesses react to increasing global demand by innovating faster and obtaining a shorter product lifecycle (PWC, 2014). Greater reliance on mobile robots is expected to result in even greater production flexibility. Unlike traditional stationary robots, mobile robots can be easily relocated throughout the production facility and reconfigured to carry out new tasks and use new tools quickly to markedly enhance product variety (Michalos et al., 2016; Michalos et al., 2015). 


\subsection{Robots across countries and industries}

OECD economies occupy a prominent position amongst the top 10 greatest users of automated machines from 1993 to 2016 (see Box 2 for more information on robotics data). The United States, Germany, Korea and Italy experienced considerable growth in their robot stock during this period. But robot investments are however not exclusive to OECD economies, with China, Chinese Taipei and Thailand having rapidly invested in robots and quickly catching up with Italy, France and Spain. The differences in robot usage across countries can be explained by higher-thanaverage wage growth, low unemployment rates and/or workforces that are rapidly ageing in developed economies. In emerging economies, the need to achieve higher quality standards is another motive for the large investments in robots.

Figure 3. Robot stock amongst top 10 using economies, 2000 to 2016
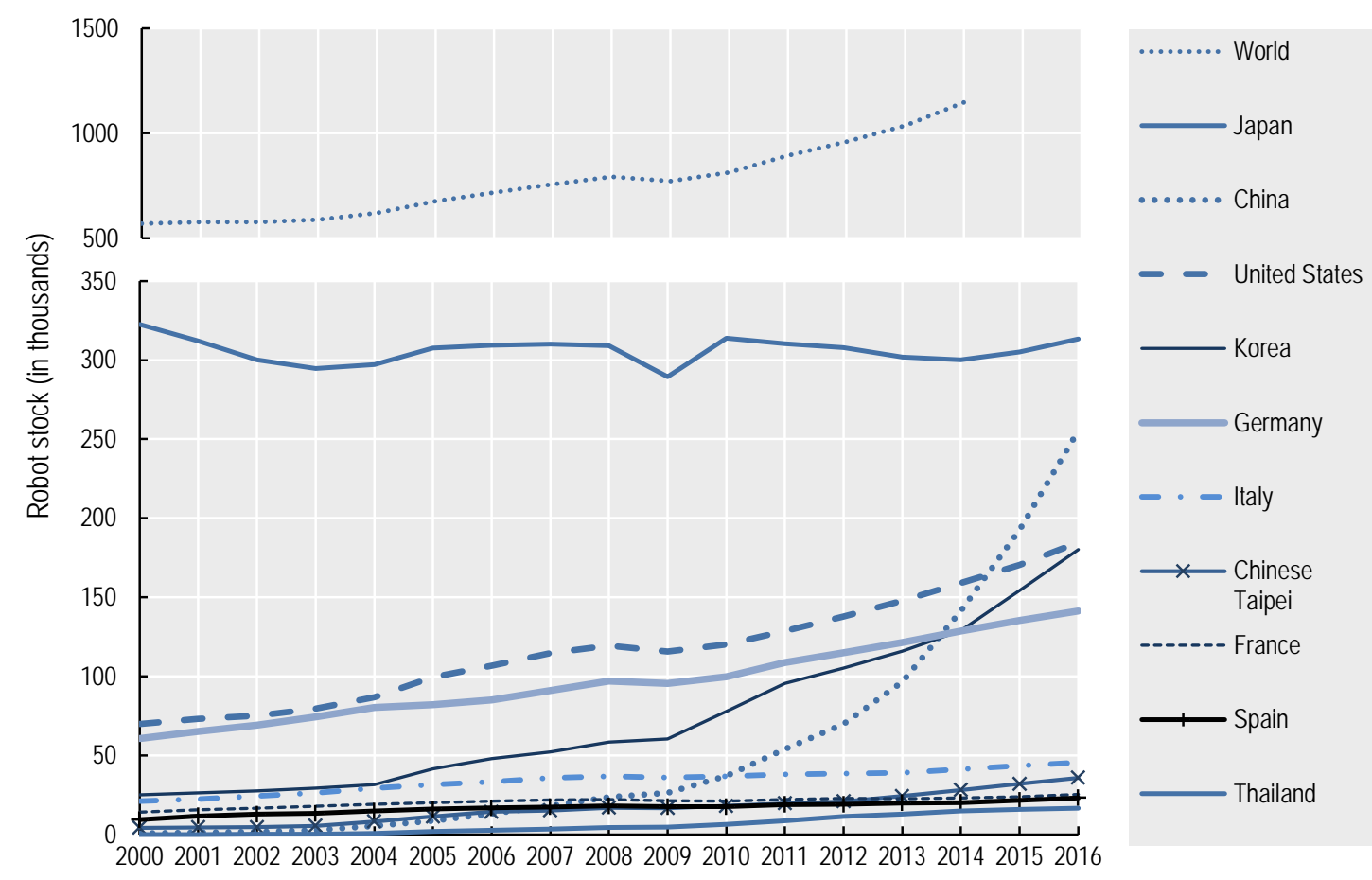

Note: Robot stock is calculated using a perpetual inventory method assuming an annual depreciation of $10 \%$. World robot stock from 2013 is absent from the IFR dataset.

Source: Calculations based on IFR (2016) 


\section{Box 2. Data on robotics}

Data on the use of robots across countries and industries are provided by the International Federation of Robotics (IFR). To our knowledge this dataset is the prominent source of global robotics statistics in existence. The definition of industrial robots used by IFR comes from the International Organization for Standardization (ISO) 8373:2012: a robot refers to "a machine that embodies the following characteristics: can be reprogrammed, is multipurpose in function, allows for physical alteration, and is mounted on an axis".

IFR constructs this dataset by consolidating information on industrial robot sales from almost every industrial robot supplier in the world. The dataset therefore contains information on annual shipments (sales) and a measure of robot stock across roughly 100 geographic locations and industries from 1993-2016. The robot stock is an estimate, based on the assumption that the average service life of a robot is 12 years. After 12 years the robot is assumed to be immediately withdrawn from service. As this is somewhat inconsistent with how the robot stock is calculated within the literature (see for example Graetz and Michaels, 2015), an alternative stock measure is calculated in this paper by, similar to Graetz and Michaels (2015), starting from the initial stock starting value from the IFR and then adding to these the robot sales from subsequent years and assuming an annual deprecation of $10 \%$. For some countries, robot stock and sales is only available at the country level for early years of the sample period. In order to overcome this, the shares of robot sales and stock across sectors in later years are used in order to allocate robots to these sectors in earlier years of the sample. ${ }^{6}$ A number of robustness tests calculating the shares with all available years and with the last year of the sample period have been performed. Sample statistics from both procedures find little difference between these two methods, hence the shares from the last sample period are used to improve the overall sectoral coverage of the data.

Robot sales and stock are denominated in units, and thus information related to the value or the quality of the assets is not included in the IFR dataset. Changes in the price of robots and/or their components (software, hardware and non-ICT related inputs) are a good indicator of increased quality of robots overtime. Figure 4 compares the current prices of robots, ICT capital and non-ICT capital over 1993-2008 in a few countries where all sets of data are available (OECD, 2016b). Indeed, the figure suggests that robot quality (proxied by the decline in price) appears to have increased over time, which may present some measurement issues in the estimations. As a robustness test, applying larger depreciation rates when calculating robot stock takes somewhat into account the increasing quality of robotics over time. Indeed, a large depreciation rate indirectly puts greater emphasis on more recent robot technologies than previous machines.

Figure 4. The price of robots, ICT and non-ICT capital (1998=100)

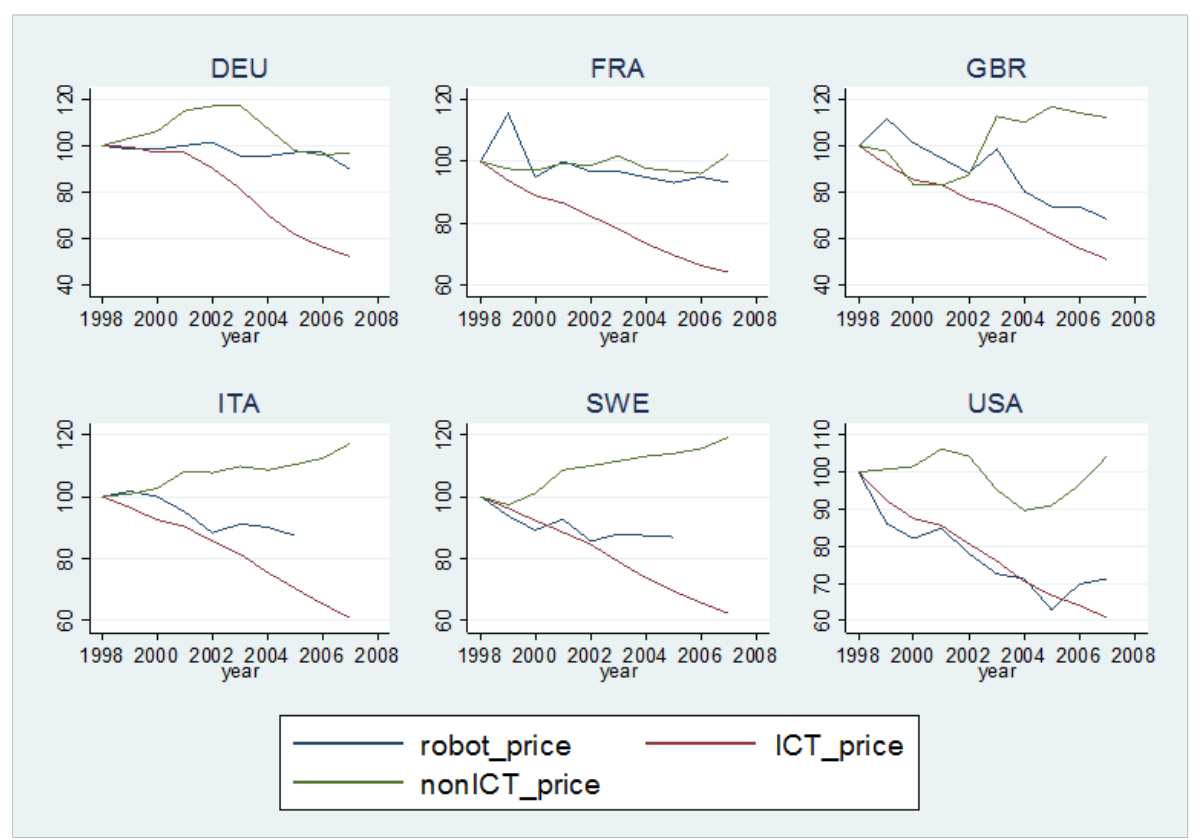

Source OECD (2016b) 
In terms of robot intensity, almost every economy experienced an increase in the number of robots per person over the sample period (Figure 5). At the same time there is considerable heterogeneity in the intensity of robot use across economies. Notably Korea uses the most robots per person with roughly 35 units per 10000 inhabitants in 2016. Japan is the second largest intensive user of robot despite a decline in robot stock over the sample period. Germany Singapore and Chinese Taipei are the next most robot intensive economies, driven particularly by the recent surge in robot investment over this period.

Figure 5. Robot intensity amongst top 25 using economies, 2016

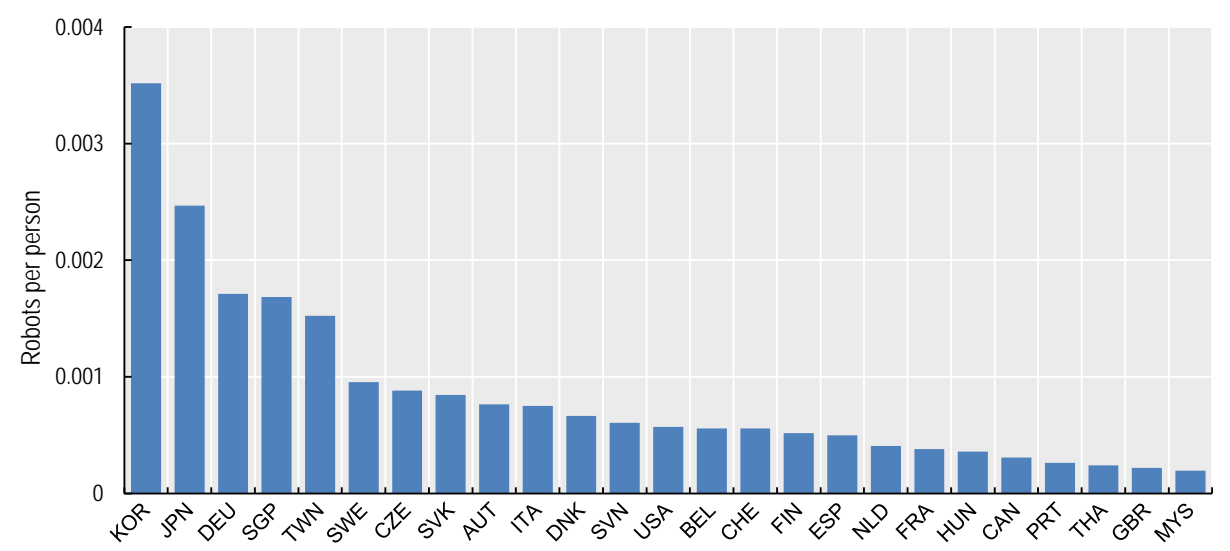

Note: Robot intensity is calculated as robot stock over population. Data for Finland and Slovenia come from 2013. Source: Calculations based on IFR (2016)

Robots are highly concentrated in a few industrial sectors ${ }^{7}$ (Figure 6): the majority of robot use (roughly $70 \%$ ) is concentrated within transport equipment, computers and electronics and chemical and mineral production and food and beverage production. For most economies, the transportation equipment sector is the largest user of industrial robots in the economy. Two exceptions to this are Korea and Chinese Taipei where the electrical and optical equipment sectors used the highest proportion of robots. In Chinese Taipei for example, 76\% of robot purchases in 2016 were made by the electronics sector, reflecting the industrial structure of the economy.

The high concentration of robots in sectors like transport equipment, including automotive and electronics, demonstrates the high stakes at play for emerging economies in Asia and elsewhere in the world. The strong export position of these economies is largely based on their low labour costs in these industries. Strong investments in robots in developed economies may quickly result in the erosion of such a competitive advantage and make these activities exposed to reshoring of activities to developed economies. In other industries where emerging economies also benefit from their lower labour costs - e.g. garment and textiles - robots have not made a big inroad and are not expect to do so quickly

The deployment of robots in industries is generally dependent on a number of factors. First, technical requirements of the production process clearly determine the (further) usage of robots as some activities and jobs are easily automatable, while others are not for the moment. Certain production tasks can only be replaced by very advanced robotics systems with a broad range of functions, which make them (too) expensive to implement. However, things are expected to change over time with higher performing robots - at a lower cost - being able to automate a growing number of activities and tasks. Second, manufacturing industries in which labour costs account for a large(r) share in total production costs are more likely to invest in robotics because robots allow to save on labour and thus costs. But, third, location is another important determinant mediating this link between labour costs and wider robotics use. Industries located in emerging economies where labour 
INDUSTRIAL ROBOTICS AND THE GLOBAL ORGANISATION OF PRODUCTION costs are typically lower, are less likely to adopt robots and automation compared to more developed (and thus higher labour cost) economies. The inflection point where robots become more cost efficient than human labour lies - ceteris paribus - further in time for emerging economies. Interestingly however, some emerging economies are observed to heavily invest in robotics as a deliberate (government) strategy in order to compensate for their fast rising labour costs and/or to compete with the growing robotics manufacturing deployed in developed economies.

Figure 6. Robot purchases by sector amongst highest users, 2016

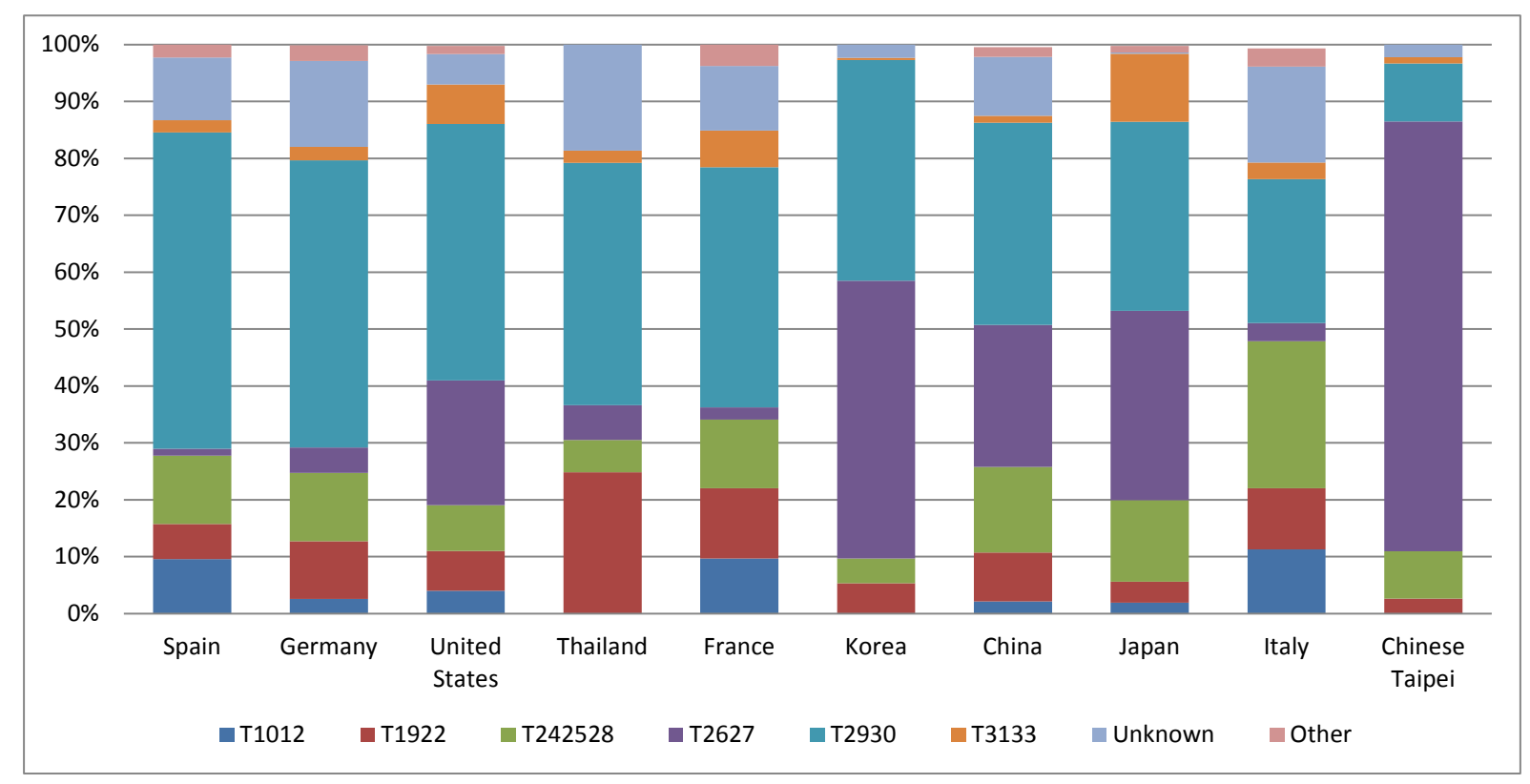

Note: Sectors classified by ISIC version 4 . See footnote below for industry classification explanation.

Source: Calculations based on IFR (2016)

A large proportion of robots are implemented to handle production operations and machine tending. In Italy, Korea, Germany and Spain, roughly 60\% of robot purchases were to assist with handling and machine tending. This typically includes functions carried out in the primary stages of production such as the handling of components, stamping, bending, measuring, quality inspection, and packaging and placing. For most economies, a considerable share of robot purchases is also used for welding and soldering. Moreover, in the United States, Chinese Taipei and to some extent Japan and Korea, a significant percentage of robots are employed in the residual category "Other applications", which refers to robots used in cleanrooms for the production of pharmaceutical products, semiconductors, flat panel displays and so on. The application of robots across economies seems to be somewhat consistent with the sectoral purchases of robots illustrated in Figure 7. 
Figure 7. Industrial robot sales by application, 2016

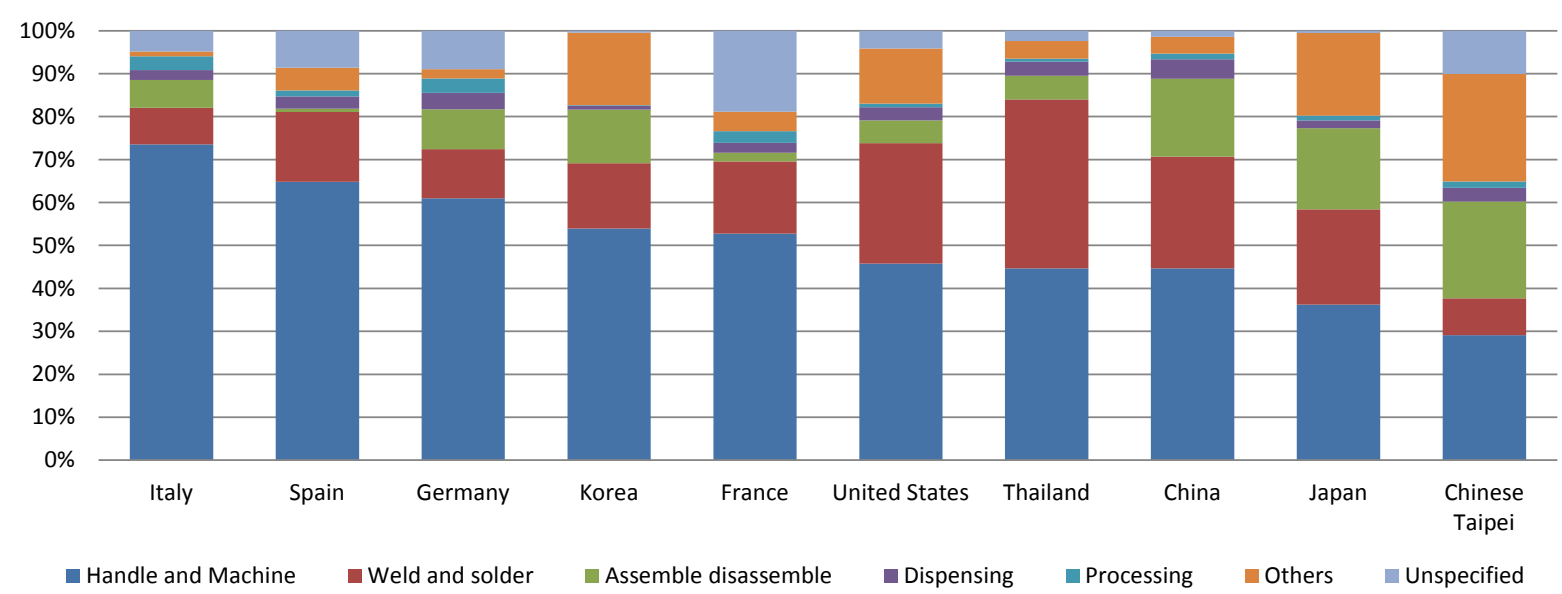

Note: Handling operations and machine tending refers to functions carried out in the primary stages of production including handling of components, stamping, bending, measuring, quality inspection, and packaging and placing. Welding and soldering refer to a range of welding activities including, Arc, Spot, Laser, Ultrasonic, Plasma welding and so on. Assemble and disassemble signify functions involved in the putting together and taking apart of products. Processing applications can include cutting, drilling and sheering of parts by a range of methods, laser, water, mechanical gas/plasma. Dispensing refers to the application of paint, adhesives and sealants as well as administering and spraying other materials. Others refer to robots used in cleanrooms for the production as well as scientific research of pharmaceutical products, semi-conductors, flat panel displays and so on. A full explanation of the applications can be found at IFR (methodology manual).

Source: Calculations based on IFR (2016) 


\section{Robotics and the location of production}

\subsection{Robotics and offshoring}

For a number of reasons larger robot usage increases the attractiveness of (developed) economies for manufacturing activities and as a result may reverse past/current offshoring trends. Offshoring to emerging economies in the past has been motivated by the search for lower labour costs, as well as being closer to large and growing consumer markets. Attracted by the large labour force in these countries, companies in developed economies - typically characterised by higher labour costs relocated (labour-intensive) activities during the past decades. Since robotics allow for labour cost savings, it can be hypothesised that this cost motive of offshoring from developed economies becomes less pressing. In combination with the rising wage costs in (some) emerging economies ${ }^{8}$ and persisting productivity differentials across countries, robotics are helping to lower the difference in the cost of production between developed and emerging economies. As robotic manufacturing becomes cheaper and offshoring more expensive, the cost/benefit analysis changes: instead of relocating activities away from home and sourcing inputs from abroad, production at home will increasingly become a viable/profitable alternative for companies.

But investments in robots are not only about saving on labour costs. Robotics are important tools to allow for more customised manufacturing, especially when artificially intelligent robots will increasingly become adaptable, programmable and autonomous. Industries in which market demand and consumer preferences change quickly have a lot to benefit from the usage of robots, when compared to the alternative of offshoring - often far away - where suppliers do not always produce according to the right specifications, resulting in quality issues and long delivery times. The deployment of robots can therefore help companies get new products to the market much quicker.

In order to test the potential effects of robotics on offshoring in this paper, the widely used Feenstra \& Hanson (1996) measure of offshoring ${ }^{9,10}$ is related to investments in robotics across countries and industries over time. As such, the focus is on how robotics may change the extent of international sourcing of intermediates. Because of the potentially different impact of robotics for developed and emerging economies ${ }^{11}$, the empirical analysis has been undertaken separately for both groups of economies. ${ }^{12}$

The results for the whole period 2000-14 for developed economies (HDC in Table 1) do not directly seem to suggest a link between the growth in robot investments and offshoring (for a detailed discussion on the empirical model and variable construction, please see Annex A). But when focusing on the more recent years 2010-14 - i.e. a period characterised by rapidly rising investments in robotics $^{13}$ - the results demonstrate a negative association of robotics investments (net of depreciation) with the growth of offshoring. Industries in developed economies that increasingly invest in robotics witness a lower growth in offshoring, i.e. a decrease in the international sourcing of intermediates. In particular, $10 \%$ growth in the robot stock appears to results in a $-0.54 \%$ growth in offshoring. Interestingly, this negative association becomes larger as the labour intensity of industries increases, suggesting that robotics (help) hinder/stop the relocation of especially labour intensive activities, as they help compensate for higher labour costs in developed economies.

No statistically significant relationship between robotics and offshoring is observed for the group of emerging economies (LDC in Table 1), suggesting that robotics have not yet affected the offshoring patterns from these economies. Nevertheless, a small interaction effect of offshoring growth and labour intensity level is observed when considering the whole period 2000-14. It is however puzzling that the effect disappears when focusing specifically on later years, i.e. the period where sizeable investments in robotics are observed in emerging economies. 
INDUSTRIAL ROBOTICS AND THE GLOBAL ORGANISATION OF PRODUCTION

Table 1. Effects of growth in robotics on the growth of offshoring

\begin{tabular}{|c|c|c|c|c|}
\hline & \multicolumn{2}{|c|}{$\mathrm{HDC}$} & \multicolumn{2}{|c|}{ LDC } \\
\hline Dependent var: Offshoring (annual growth) & $2000-2014$ & $2010-2014$ & $2000-2014$ & $2010-2014$ \\
\hline \multirow[t]{2}{*}{ Robot stock (annual growth) } & -0.005 & $-0.054^{\star \star}$ & -0.039 & 0.000 \\
\hline & $(0.02)$ & $(0.03)$ & $(0.03)$ & $(0.03)$ \\
\hline \multirow[t]{2}{*}{ Robot stock *Labour Intensity } & 0.000 & $-0.020^{*}$ & $-0.026^{\star}$ & -0.008 \\
\hline & $(0.01)$ & $(0.01)$ & $(0.01)$ & $(0.01)$ \\
\hline \multirow[t]{2}{*}{ Labour Intensity } & 0.013 & 0.011 & $-0.026^{\star \star}$ & -0.001 \\
\hline & $(0.01)$ & $(0.02)$ & $(0.01)$ & $(0.03)$ \\
\hline \multicolumn{5}{|l|}{ Control Variables } \\
\hline Year & $\checkmark$ & $\checkmark$ & $\checkmark$ & $\checkmark$ \\
\hline Country*Industry & $\checkmark$ & $\checkmark$ & $\checkmark$ & $\checkmark$ \\
\hline R-squared & 0.224 & 0.304 & 0.220 & 0.303 \\
\hline Observations & 5427 & 1937 & 1763 & 601 \\
\hline
\end{tabular}

\subsection{Robotics and reshoring}

The previous analysis suggests that robotics slow down - and in some cases, stop offshoring and thus help to keep manufacturing activities in developed economies. A different question is if investments in robots will lead to the actual reshoring of activities to developed economies, i.e. bringing activities that were once offshored back home. De Backer et al., (2016) have discussed the motivations of reshoring and tried to assess the importance of reshoring in more aggregate terms beyond the typical anecdotal and survey evidence. Acknowledging that aggregate indicators (e.g. the share of imported intermediates from emerging economies, the geographical concentration of resources within MNEs) are only an indirect measure of reshoring, they show that the evidence of reshoring at the aggregate level (industry and economy-wide) is overall rather limited. In analysing the (re-)allocation of resources abroad and at home within MNE groups based on firmlevel data, some evidence of reshoring in terms of capital investments was found but not in terms of employment. One explanation for these trends might be the growing importance of robotics, which are very capital intensive investments, but at the same time labour-saving. This is also one of the reasons why the employment impact of reshoring in developed economies may be rather limited, and not lead to the manufacturing renaissance of (certain) OECD economies as some have advocated.

In order to check if this explanation holds, two different analyses are undertaken using two different measures of reshoring. First, a similar analysis as in the previous section on offshoring is used of linking the aggregate indicator of "imports over domestic demand" to investment in robots across countries and industries. Instead of focusing only on the international sourcing of inputs like the Hanson and Feenstra measure above, this indicator takes into account intermediates, as well as final products, to calculate what share of domestic demand is served by foreign products. As argued in De Backer et al. (2016), this measure shows an increasing trend if the reshoring of activities becomes more important. The results (presented in Annex B see Table B1.1), however, do not show any effect of robotics on this aggregate but broad measure of reshoring. For example, robot investment in developed and emerging economies - both over the whole period as well as in more recent years - is not significantly correlated with imports as a percentage of domestic demand. 
INDUSTRIAL ROBOTICS AND THE GLOBAL ORGANISATION OF PRODUCTION

A second exercise extends the empirical firm-level analysis as in De Backer et al., (2016) and includes investment in robots at the country-industry level (please see Annex A for a detailed discussion on the empirical model and variable construction). The idea is to check if within MNE groups a transfer of productive resources (i.e. fixed capital and employment) takes place from affiliates abroad to the headquarters and affiliates at home ${ }^{14}$ because of robotics investments. Interestingly, the results - now including more recent years - for the group of developed economies do show - contrary to De Backer et al., (2016) - indications of backshoring both in terms of capital investments and employment over the period 2003-14: i.e., a negative change in aggregate employment abroad is associated with a positive employment growth in the home country within the same business group. Focusing on the more recent time period of 2010-14 shows that reshoring in terms of employment has become more important especially in recent years, which gives some support to the claims about the growing importance of this phenomenon in recent years.

Augmenting the model with investment in robots- by interacting the negative/positive growth abroad with robots investments in order to see if there is more reshoring to home countries where robots investments are relatively more important ${ }^{15}$ - does however not get support from the model (Table 2). No extra effect is observed from robotics on the reshoring of productive resources to developed home countries, neither in terms of fixed capital or employment. Also recent reshoring seems not to be driven by investments in robotics, i.e. home countries investing strongly in robotics do not witness a stronger reshoring of jobs in 2010-14. All in all, while robotics seems to have a negative effect on the pace of offshoring, the results suggest that robots do not (yet) trigger a reshoring of activities to developed economies. 
Table 2. Effects of growth in robotics on backshoring within MNEs

\begin{tabular}{|c|c|c|c|c|c|c|c|c|}
\hline \multirow{2}{*}{$\begin{array}{l}\text { Country sample } \\
\text { Dependent variable } \\
\end{array}$} & \multicolumn{4}{|c|}{ Highly Developed Countries \& All Years } & \multicolumn{4}{|c|}{ Highly Developed Countries \& 2010-2014 } \\
\hline & \multicolumn{4}{|c|}{ Yearly Growth Rate } & & & & \\
\hline & \multicolumn{2}{|c|}{ Fixed Assets } & \multicolumn{2}{|c|}{ Employment } & \multicolumn{2}{|c|}{ Fixed Assets } & \multicolumn{2}{|c|}{ Employment } \\
\hline \multirow[t]{2}{*}{ Growth abroad (positive) } & 0.000254 & -0.000148 & -0.00110 & -0.00157 & 0.000679 & 0.000844 & -0.00203 & -0.00185 \\
\hline & $(0.00384)$ & $(0.00390)$ & $(0.00229)$ & $(0.00229)$ & $(0.00519)$ & $(0.00522)$ & $(0.00331)$ & $(0.00331)$ \\
\hline \multirow[t]{2}{*}{ Growth abroad pos*robot stock } & & -0.0124 & & -0.00403 & & -0.00141 & & $0.0245^{*}$ \\
\hline & & $(0.0108)$ & & $(0.00639)$ & & $(0.0157)$ & & $(0.0134)$ \\
\hline \multirow[t]{2}{*}{ Growth abroad (negative) } & $-0.0123^{*}$ & $-0.0131^{\star *}$ & $-0.00827^{*}$ & -0.00731 & -0.00295 & -0.00354 & $-0.0125^{\star \star}$ & $-0.0116^{*}$ \\
\hline & $(0.00633)$ & $(0.00632)$ & $(0.00494)$ & $(0.00498)$ & $(0.00869)$ & $(0.00861)$ & $(0.00602)$ & $(0.00600)$ \\
\hline \multirow[t]{2}{*}{ Growth abroad neg*robot stock } & & -0.0229 & & 0.0107 & & -0.0344 & & 0.00156 \\
\hline & & $(0.0203)$ & & $(0.0174)$ & & $(0.0278)$ & & $(0.00699)$ \\
\hline \multirow[t]{2}{*}{ Growth in robot stock } & & 0.00114 & & 0.00828 & & -0.00649 & $0.900^{\star \star \star}$ & $0.906^{\star * \star}$ \\
\hline & & $(0.00759)$ & & $(0.00504)$ & & $(0.0117)$ & $(0.0413)$ & $(0.0417)$ \\
\hline \multirow[t]{2}{*}{ Ave growth group 2003-2014 } & $0.915^{\star \star \star}$ & $0.914^{\star \star \star}$ & $0.894^{\star \star \star}$ & $0.898^{\star * *}$ & $0.942^{\star \star \star}$ & 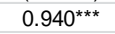 & $0.900^{\star * \star}$ & $0.906^{\star \star \star}$ \\
\hline & $(0.0345)$ & $(0.0346)$ & $(0.0308)$ & $(0.0311)$ & $(0.0495)$ & $(0.0498)$ & $(0.0413)$ & $(0.0417)$ \\
\hline \multicolumn{9}{|l|}{ Control Variables } \\
\hline Industry*Year & $\checkmark$ & $\checkmark$ & $\checkmark$ & $\checkmark$ & $\checkmark$ & $\checkmark$ & $\checkmark$ & $\checkmark$ \\
\hline Country & $\checkmark$ & $\checkmark$ & $\checkmark$ & $\checkmark$ & $\checkmark$ & $\checkmark$ & $\checkmark$ & $\checkmark$ \\
\hline R-squared & 0.036 & 0.036 & 0.032 & 0.032 & 0.039 & 0.039 & 0.033 & 0.033 \\
\hline Observations & 57349 & 57087 & 69597 & 69261 & 30939 & 30751 & 41193 & 40931 \\
\hline
\end{tabular}

\subsection{Robotics and the reallocation of resources within MNEs}

The reallocation of resources within MNE networks is not a two-way street between affiliates abroad and the headquarters at home but instead happens between all affiliates mutually. By broadening the analysis beyond the reshoring of MNE activities to home countries, the potential effect of robotics on the total reallocation of resources across affiliates within MNE groups can be analysed. Because of their international networks, MNEs have a large (strategic and operational) flexibility in moving resources from one place to the other. The labour savings and increased production flexibility from robot use enable MNEs to shift production to other countries, for example by locating production closer to the end customer so they can tailor and design goods based on the changing interests of the local market. Firms with plant facilities in multiple countries can quickly transfer product designs through CAD/CAM files between teams of robots making it easier for firms to shift production needs throughout the world. Greater advances in cloud computing and machine to machine communication will also facilitate real-time learning between robots in different locations and increase the responsiveness and efficiency of production (PWC, 2014).

The objective of the next empirical analysis thus is to analyse if the (re-)allocation of productive resources within MNEs shifts relatively more towards countries that invest (more) heavily in robotics. Similar to the previous analyses on offshoring and reshoring, the discussion focuses on how robotics may increase the attractiveness of countries for manufacturing activities, but now in particular for investment by (foreign and domestic) MNEs. The same firm-level information on fixed capital and employment as in the previous analysis is used but now at the level of individual MNE affiliates, again linked to robotics stock in the country of the affiliate ${ }^{16}$ (see Annex A for details on the empirical model and data construction).

The results (Table 3) lend some support for the hypothesis that the reallocation of resources across MNE affiliates is driven in part by investment in robotics. A positive correlation of robot investment on employment growth is observed for developed economies. In particular the results suggest that affiliates located in economies with strong growth in robotics investments, relative to the average group growth of the MNE, seem to attract larger resources in terms of jobs. However, there is no effect on capital investment, and the employment effect disappears when focusing on only the more recent years 2010-2014. This may be due to the growing investments in some emerging economies during this period (UNCTAD, 2014), which is also consistent with the significance and 
INDUSTRIAL ROBOTICS AND THE GLOBAL ORGANISATION OF PRODUCTION size of the coefficient on fixed asset growth of the group. However, no effect of robotics on the reallocation of fixed capital and employment within MNEs are found for developing economies ${ }^{17}$.

Table 3. Effects of growth in robotics on the reallocation of resources within MNEs

\begin{tabular}{|c|c|c|c|c|c|c|c|c|}
\hline \multirow{3}{*}{$\begin{array}{l}\text { Country sample } \\
\text { Time period } \\
\text { Dependent var } \\
\end{array}$} & \multicolumn{4}{|c|}{ HDC countries } & \multicolumn{4}{|c|}{ LDC countries } \\
\hline & \multicolumn{2}{|c|}{ 2003-2014 } & \multicolumn{2}{|c|}{$2010-2014$} & \multicolumn{2}{|c|}{ 2003-2014 } & \multicolumn{2}{|c|}{$2010-2014$} \\
\hline & Employment & Fixed asset & Employment & Fixed asset & Employment & Fixed asset & Employment & Fixed asset \\
\hline \multirow[t]{2}{*}{ Robot of affiliate } & $0.015^{\star \star \star}$ & 0.006 & 0.005 & -0.001 & -0.008 & -0.029 & -0.063 & -0.041 \\
\hline & 0.00 & $(0.01)$ & $(0.01)$ & $(0.02)$ & $(0.02)$ & $(0.03)$ & $(0.04)$ & $(0.04)$ \\
\hline \multirow[t]{2}{*}{ Demand } & 0.001 & 0.002 & -0.004 & 0.036 & -0.016 & 0.016 & 0.004 & -0.037 \\
\hline & $(0.01)$ & $(0.01)$ & $(0.01)$ & $(0.02)$ & $(0.02)$ & $(0.05)$ & $(0.05)$ & $(0.07)$ \\
\hline \multirow[t]{2}{*}{ Employment growth of group } & $0.117^{\star \star \star}$ & & $0.113^{\star \star \star}$ & & $0.325^{\star \star *}$ & & $0.296^{\star \star \star}$ & \\
\hline & $(0.01)$ & & $(0.01)$ & & $(0.04)$ & & $(0.03)$ & \\
\hline \multirow{2}{*}{ Fixed asset growth of group } & & $0.124^{\star \star \star}$ & & $0.122^{\star \star \star}$ & & $0.168^{\star \star \star}$ & & $0.162^{\star \star \star}$ \\
\hline & & $(0.01)$ & & $(0.01)$ & & $(0.02)$ & & $(0.02)$ \\
\hline \multicolumn{9}{|l|}{ Control variables } \\
\hline sector*year & $\checkmark$ & $\checkmark$ & $\checkmark$ & $\checkmark$ & $\checkmark$ & $\checkmark$ & $\checkmark$ & $\checkmark$ \\
\hline country*year & $\checkmark$ & $\checkmark$ & $\checkmark$ & $\checkmark$ & $\checkmark$ & $\checkmark$ & $\checkmark$ & $\checkmark$ \\
\hline R-squared & 0.036 & 0.014 & 0.029 & 0.011 & 0.129 & 0.04 & 0.145 & 0.038 \\
\hline Observations & 330665 & 300574 & 179872 & 156501 & 59752 & 58127 & 27015 & 26072 \\
\hline
\end{tabular}




\section{Robotics and GVC integration and upgrading}

Given that robotics influence the location of production and off- and reshoring patterns to some extent, it can be hypothesised that also the activities of countries within GVCs may be impacted upon by robotics. In particular, robot usage may affect the integration or participation in GVCs as well as the upgrading trajectories of countries within GVCs. Because of the differences reported above, different impacts can be expected for developed and emerging economies. For example, better production efficiency, and higher quality obtained through robot adoption, could make it easier for firms in emerging economies to begin participating within GVCs. This would mean that the extent of participation in GVCs will be determined by the (lack of) adoption of robots in these countries.

Robots may equally affect the position of countries/industries within GVCs as they may induce firms to carry out higher value added activities through both process and product upgrading. The use of robots, like other forms of knowledge based capital, may allow firms to carry out higher value added activities within the value chain. Anecdotally, robots have become a key input in production for certain high-quality products, such as in the automotive, aeronautical and electronics sectors. One of the major benefits of robotics, for example, seems to be the potential to standardise quality, and influence the production of new complex products. By retooling production lines with automated and robotic systems, firms may achieve greater production performance with higher efficiency, fewer product defaults, and greater flexibility in processing orders, resulting in process upgrading. In addition, employing robots may also enhance a firm's ability to introduce newly designed, high quality goods more efficiently than competitors, thereby enabling product upgrading (OECD, 2013). These potential performance implications would be consistent with the results reported in Graetz and Michaels (2015) that showed value added and productivity gains over time of robotics.

The empirical strategy is similar to that used in the analysis on offshoring, linking the change in different GVCs indicators (upgrading, comparative advantage, forward/backward participation) to the changes in robot stocks ${ }^{18,19}$ across countries and industries. However, instead of including a number of control variables, a (simple) reduced model is used for this analysis, incorporating appropriate fixed effects (see Annex A for a description of the empirical model and the construction of the variables).

The results suggest that the impact of robotics on GVC integration for emerging economies is not (yet) observable (Table 4). This most likely reflects the same finding cited above, in which the effects of robots on off/re-shoring and re-allocation in these economies were very small to nonexistent. No effects of robots are observed in terms of comparative advantage, forward and backward participation of emerging economies. There is a (small) positive effect of robotics on GVC upgrading however observed when accounting for a somewhat longer time perspective (in particular the two year moving average robot stock) for the most recent 2010-14 period characterised by significant investment in robots in emerging economies. This may suggest that these investments in robotics are beginning to influence the quality of goods produced in emerging markets, which may potentially strengthen over time. But it is clear that this would need confirmation in follow-up research using more recent data.

The effects of robotics on GVC activities of developed economies however are somewhat more pronounced in the empirical results. Positive effects, albeit small, of robotics on forward participation, in the later years of the sample are observed (for annual growth as well as two and three year moving averages). In addition, investments in robotics also seem to be associated with GVC upgrading for developed economies in international markets in the 2010-14 period (again for annual growth and average growth over two and three years). Together these results suggest that robotics can become an important source of capital for creating higher quality goods, achieving higher productivity and climbing the value chain. 
Overall, the analysis seem to provide some preliminary evidence for potential effects of robots on GVC integration and upgrading, for developed economies but less so for emerging markets. One explanation could be that the effects on structural GVC characteristics like participation and upgrading take time to materialise, hence the need maybe for a longer time horizon to study these types of effects. This is consistent with the fact the relationship between robots and GVC indicators occur mostly in the later period of the sample. The uptake of robots investments only in very recent years particularly in emerging economies would then explain the lack of supportive indications in the analysis. 
INDUSTRIAL ROBOTICS AND THE GLOBAL ORGANISATION OF PRODUCTION

Table 4. Effects of growth in robotics on GVC upgrading

\begin{tabular}{|c|c|c|c|c|c|c|c|c|c|c|c|c|}
\hline \multirow{2}{*}{$\begin{array}{l}\text { Dependent var: (annual growth) } \\
\text { Sample countries } \\
\end{array}$} & \multicolumn{12}{|c|}{ Domestic Value Added Share of Exports } \\
\hline & \multicolumn{2}{|c|}{ HDC } & \multicolumn{2}{|c|}{ HDC } & \multicolumn{2}{|c|}{ HDC } & \multicolumn{2}{|c|}{ LDC } & \multicolumn{2}{|c|}{ LDC } & \multicolumn{2}{|c|}{ LDC } \\
\hline Sample period & $2000-2014$ & $2010-2014$ & $2000-2014$ & $42010-2014$ & $2000-2014$ & $2010-2014$ & $2000-2014$ & $42010-2014$ & $2000-2014$ & $2010-2014$ & $2000-20142$ & 2010-2014 \\
\hline \multirow[t]{2}{*}{ Robot stock (annual growth) } & 0.002 & $0.010^{\star \star}$ & & & & & -0.003 & 0.003 & & & & \\
\hline & $(0.00)$ & $(0.00)$ & & & & & $(0.00)$ & $(0.00)$ & & & & \\
\hline \multirow[t]{2}{*}{ Robot stock (two year average) } & & & 0.003 & $0.015^{\star \star}$ & & & & & -0.002 & $0.011^{*}$ & & \\
\hline & & & $(0.00)$ & $(0.01)$ & & & & & $(0.00)$ & $(0.01)$ & & \\
\hline \multirow[t]{2}{*}{ Robot stock (three year average) } & & & & & 0.005 & $0.017^{*}$ & & & & & 0.003 & 0.007 \\
\hline & & & & & $(0.00)$ & $(0.01)$ & & & & & $(0.01)$ & $(0.01)$ \\
\hline & & & & & & & & & & & & \\
\hline \multicolumn{13}{|l|}{ Control Variables } \\
\hline Year & $\checkmark$ & $\checkmark$ & $\checkmark$ & $\checkmark$ & $\checkmark$ & $\checkmark$ & $\checkmark$ & $\checkmark$ & $\checkmark$ & $\checkmark$ & $\checkmark$ & $\checkmark$ \\
\hline Country*Industry & $\checkmark$ & $\checkmark$ & $\checkmark$ & $\checkmark$ & $\checkmark$ & $\checkmark$ & $\checkmark$ & $\checkmark$ & $\checkmark$ & $\checkmark$ & $\checkmark$ & $\checkmark$ \\
\hline R-squared & 0.218 & 0.302 & 0.223 & 0.302 & 0.221 & 0.301 & 0.151 & 0.216 & 0.158 & 0.217 & 0.164 & 0.216 \\
\hline Observations & 7429 & 2673 & 6889 & 2662 & 6338 & 2640 & 2619 & 949 & 2425 & 941 & 2223 & 925 \\
\hline
\end{tabular}


Table 5. Effects of growth in robotics on comparative advantage

\begin{tabular}{|c|c|c|c|c|c|c|c|c|c|c|c|c|}
\hline Dependent var: (annual growth) & \multicolumn{12}{|c|}{ Relative Comparitive Advantage } \\
\hline Sample countries & \multicolumn{2}{|c|}{ HDC } & \multicolumn{2}{|c|}{ HDC } & \multicolumn{2}{|c|}{ HDC } & \multicolumn{2}{|c|}{ LDC } & \multicolumn{2}{|c|}{ LDC } & \multicolumn{2}{|c|}{ LDC } \\
\hline Sample period & $2000-2014$ & $2010-2014$ & $2000-2014$ & $2010-2014$ & $2000-2014$ & $42010-2014$ & $2000-2014$ & 2010-2014 & $2000-20142$ & 2010-2014 & $2000-2014$ & $2010-2014$ \\
\hline \multirow[t]{2}{*}{ Robot stock (annual growth) } & 0.010 & 0.005 & & & & & 0.008 & 0.003 & & & & \\
\hline & $(0.01)$ & $(0.02)$ & & & & & $(0.01)$ & $(0.02)$ & & & & \\
\hline \multirow[t]{2}{*}{ Robot stock (two year average) } & & & 0.016 & 0.007 & & & & & 0.004 & -0.001 & & \\
\hline & & & $(0.01)$ & $(0.02)$ & & & & & $(0.02)$ & $(0.03)$ & & \\
\hline \multirow[t]{2}{*}{ Robot stock (three year average) } & & & & & $0.026^{*}$ & 0.040 & & & & & -0.004 & 0.036 \\
\hline & & & & & $(0.01)$ & $(0.03)$ & & & & & $(0.02)$ & $(0.05)$ \\
\hline \multirow{2}{*}{\multicolumn{13}{|c|}{ Control Variables }} \\
\hline & & & & & & & & & & & & \\
\hline Year & $\checkmark$ & $\checkmark$ & $\checkmark$ & $\checkmark$ & $\checkmark$ & $\checkmark$ & $\checkmark$ & $\checkmark$ & $\checkmark$ & $\checkmark$ & $\checkmark$ & $\checkmark$ \\
\hline Country*Industry & $\checkmark$ & $\checkmark$ & $\checkmark$ & $\checkmark$ & $\checkmark$ & $\checkmark$ & $\checkmark$ & $\checkmark$ & $\checkmark$ & $\checkmark$ & $\checkmark$ & $\checkmark$ \\
\hline R-squared & 0.077 & 0.178 & 0.082 & 0.178 & 0.091 & 0.179 & 0.149 & 0.165 & 0.151 & 0.165 & 0.153 & 0.165 \\
\hline Observations & 7420 & 2671 & 6880 & 2660 & 6330 & 2638 & 2607 & 950 & 2415 & 942 & 2215 & 926 \\
\hline
\end{tabular}


INDUSTRIAL ROBOTICS AND THE GLOBAL ORGANISATION OF PRODUCTION

Table 6. Effects of growth in robotics on backward participation

\begin{tabular}{|c|c|c|c|c|c|c|c|c|c|c|c|c|}
\hline Dependent var: (annual growth) & \multicolumn{12}{|c|}{ Backward Participation } \\
\hline Sample countries & \multicolumn{2}{|c|}{ HDC } & \multicolumn{2}{|c|}{ HDC } & \multicolumn{2}{|c|}{ HDC } & \multicolumn{2}{|c|}{ LDC } & \multicolumn{2}{|c|}{ LDC } & \multicolumn{2}{|c|}{ LDC } \\
\hline Sample period & $2000-2014$ & 2010-2014 & $2000-20142$ & $2010-2014$ & $2000-2014$ & $42010-2014$ & $2000-2014$ & 4 2010-2014 & $2000-2014$ & $2010-2014$ & $2000-2014$ & 2010-2014 \\
\hline Robot stock (annual growth) & -0.004 & $-0.020^{*}$ & & & & & 0.010 & -0.005 & & & & \\
\hline & $(0.00)$ & $(0.01)$ & & & & & $(0.01)$ & $(0.01)$ & & & & \\
\hline Robot stock (two year average) & & & -0.005 & -0.017 & & & & & 0.013 & -0.017 & & \\
\hline & & & $(0.00)$ & $(0.01)$ & & & & & $(0.01)$ & $(0.01)$ & & \\
\hline Robot stock (three year average) & & & & & -0.005 & -0.011 & & & & & 0.015 & 0.000 \\
\hline & & & & & $(0.00)$ & $(0.01)$ & & & & & $(0.01)$ & $(0.02)$ \\
\hline Control Variables & & & & & & & & & & & & \\
\hline Year & $\checkmark$ & $\checkmark$ & $\checkmark$ & $\checkmark$ & $\checkmark$ & $\checkmark$ & $\checkmark$ & $\checkmark$ & $\checkmark$ & $\checkmark$ & $\checkmark$ & $\checkmark$ \\
\hline Country*Industry & $\checkmark$ & $\checkmark$ & $\checkmark$ & $\checkmark$ & $\checkmark$ & $\checkmark$ & $\checkmark$ & $\checkmark$ & $\checkmark$ & $\checkmark$ & $\checkmark$ & $\checkmark$ \\
\hline R-squared & 0.245 & 0.317 & 0.254 & 0.315 & 0.251 & 0.314 & 0.208 & 0.165 & 0.216 & 0.165 & 0.226 & 0.164 \\
\hline Observations & 7429 & 2673 & 6889 & 2662 & 6338 & 2640 & 2622 & 952 & 2,428 & 944 & 2226 & 928 \\
\hline
\end{tabular}


Table 7. Effects of growth in robotics on forward participation

\begin{tabular}{|c|c|c|c|c|c|c|c|c|c|c|c|c|}
\hline Dependent var: (annual growth) & \multicolumn{12}{|c|}{ Forward Participation } \\
\hline Sample countries & \multicolumn{2}{|c|}{ HDC } & \multicolumn{2}{|c|}{ HDC } & \multicolumn{2}{|c|}{\begin{tabular}{l|l} 
HDC & \\
\end{tabular}} & \multicolumn{2}{|c|}{$\begin{array}{r}\text { LDC } \\
\end{array}$} & \multicolumn{2}{|c|}{ LDC } & \multicolumn{2}{|c|}{ LDC } \\
\hline Sample period & $2000-2014$ & $2010-2014$ & $2000-2014$ & 2010-2014 & $2000-2014$ & $42010-2014$ & $2000-20142$ & 2010-2014 & $2000-2014$ & $42010-2014$ & $2000-2014$ & $2010-2014$ \\
\hline \multirow{2}{*}{ Robot stock (annual growth) } & 0.002 & $0.037^{\star \star}$ & & & & & 0.003 & 0.006 & & & & \\
\hline & $(0.01)$ & $(0.02)$ & & & & & $(0.01)$ & $(0.02)$ & & & & \\
\hline \multirow[t]{2}{*}{ Robot stock (two year average) } & & & 0.003 & $0.052^{\star *}$ & & & & & 0.000 & 0.024 & & \\
\hline & & & $(0.01)$ & $(0.02)$ & & & & & $(0.02)$ & $(0.04)$ & & \\
\hline \multirow[t]{2}{*}{ Robot stock (three year average) } & & & & & -0.005 & 0.033 & & & & & 0.008 & -0.034 \\
\hline & & & & & $(0.02)$ & $(0.03)$ & & & & & $(0.03)$ & $(0.07)$ \\
\hline & & & & & & & & & & & & \\
\hline \multicolumn{13}{|l|}{ Control Variables } \\
\hline Year & $\checkmark$ & $\checkmark$ & $\checkmark$ & $\checkmark$ & $\checkmark$ & $\checkmark$ & $\checkmark$ & $\checkmark$ & $\checkmark$ & $\checkmark$ & $\checkmark$ & $\checkmark$ \\
\hline Country*Industry & $\checkmark$ & $\checkmark$ & $\checkmark$ & $\checkmark$ & $\checkmark$ & $\checkmark$ & $\checkmark$ & $\checkmark$ & $\checkmark$ & $\checkmark$ & $\checkmark$ & $\checkmark$ \\
\hline R-squared & 0.084 & 0.148 & 0.091 & 0.147 & 0.100 & 0.146 & 0.138 & 0.178 & 0.141 & 0.18 & 0.142 & 0.179 \\
\hline Observations & 7420 & 2671 & 6880 & 2660 & 6330 & 2638 & 2602 & 945 & 2411 & 937 & 2211 & 921 \\
\hline
\end{tabular}




\section{Policy aspects on robotics, GVCs and competitiveness}

\subsection{Government policies on robotics investment and usage}

There is evidence of large differences in robot adoption across countries. This is partially driven by structural characteristics of countries (wage growth, ageing, sector composition, etc.) and of industries ("physical" degree of automation, location, etc.). But also dedicated government policies may explain part of these differences. A number of governments, in developed as well as emerging economies, have identified robotics as a key economic driver for their future and have implemented policies to promote research, development and adoption of robotics in industries and companies. The policy aspects of robotics are however broader than purely economic, hence larger investment and usage of robots will call for new policies across a wide range of domains (labour markets, productivity, liability, transparency and trust, technology development, etc.). ${ }^{20}$

Policies to promote the development, investment and usage of robotics cover different policy domains including research, innovation, technology development, entrepreneurship and start-ups, etc. Ministries responsible for research in a number of countries are funding research centres on robotics, while several countries are also targeting artificial intelligence and other (digital) technologies. Innovation policies are also helping robotics from a horizontal perspective with sometimes a special focus on robotics applications. In addition and complementary to this, business/economy ministries in countries sometimes provide special conditions for (start-up) companies in robotics. In what follows, some of these policy measures in a number of economies are discussed in more detail, without, however, aiming to be exhaustive in terms of the number of economies or policy measures implemented. ${ }^{21}$

Among developed economies, Korea has heavily promoted the uptake of robots in its manufacturing industries. Government policies have been implemented on the supply side - i.e. to develop robotics technologies and support the robotics industry - and the demand side - to encourage investments in robots in downstream industries (see Box 3).

\section{Box 3. Robots policy and industry in Korea}

Like other developed countries, an ageing population, the growing labour shortage, the increasing demand for security in response to natural disaster, and the need for productivity growth, has pushed Korea to increase the usage of industrial robots. Before 2000, the robot industry in Korea was mainly driven by the growth of automobile, electronics, semi-conductor industries. After the Asian crisis, the Korean government selected several industries as a new growth engine sector for the future: the robot industry was one of these growth engines. Since then, various policies on robotics development have been implemented, including the support of R\&D investment in the robot industry. For example, the Korean government established a "New Strategy and Vision for Robot Industry" in 2005 and announced it would USD 692 million in R\&D investment over 10 years.

In 2008, the "Intelligent Robot development and dissemination Promotion Law" was enacted, a special law to promote the development and distribution of intelligent robots. Under this Act, a public initiated pilot program for the creation of a robot market was planned, and vast R\&D investment to promote innovation was put into place. Based on this special law, the First Five Year Master Plan for the intelligent robot industry was announced in 2009, creating the infrastructure for the robot industry, including R\&D investment and pursuing a pilot project for the creation of a robot market.

In July 2014, the Korean government prepared the Second Five Year Master Plan for the intelligent robot industry, which will end in 2018. Unlike the 2009 plan, this plan aimed to expand the use of robot technology into other industrial sectors, such as manufacturing and services. The goals of this masterplan are to: expand the robot market from USD 2.2 billion in 2013 to USD 7 billion by 2018; increase the number of robot companies and average sales; conduct robot R\&D; raise robot demand across all industries; construct ecosystems for the robot 
industry; and pursue private-public investment. In addition, the plan also aims to increase robot demand based on the business service models along with securing the core technology.

The robotics industry in Korea has grown rapidly over the past decade. After the Korean Robot Act was implemented in 2008, the industry reached an average annual growth rate of $21 \%$. Since 2010, when the First Five Year Master Plan for the intelligent robot industry was launched, government investment increased considerably. From 2005 to 2014, the total volume of robots produced in Korea increased from USD 326 million to 2.4 billion. From 2009 to 2014, robot sales increased from USD 842 million to 2.6 billion and over the same period, exports grew from USD 83 million to 679 million, while employment increased from 5068 to 13823 . The Korean robot market is expected to expand steadily until 2020.

Figure 8. The volume of robots produced in Korea USD, millions

Source: KIRIA

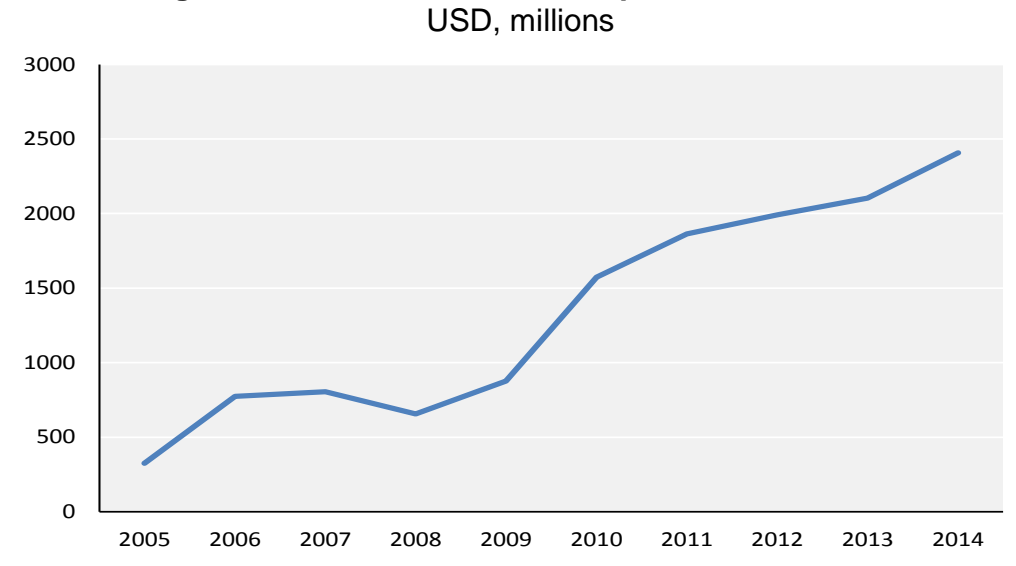

Distinguishing robots by category, the industrial robot market in Korea has led the growth of the whole robot market by reaching USD 1789 million in 2014. Automobiles and electronics are two driving forces to expand the usage of industrial robot and continue to surge. The non-industrial robot markets in specialised, personal and components are smaller than that of the industrial robot market, but the market size of those non-industrial robots is expected to grow faster in the future. Non-industrial robotics are used in the military, medical and education sector as well as households. As of $2014,70 \%$ of the industrial robots produced in Korea were used in the domestic market and $30 \%$ were exported.

Figure 9. Value of robots produced in Korea by category Billions of Won

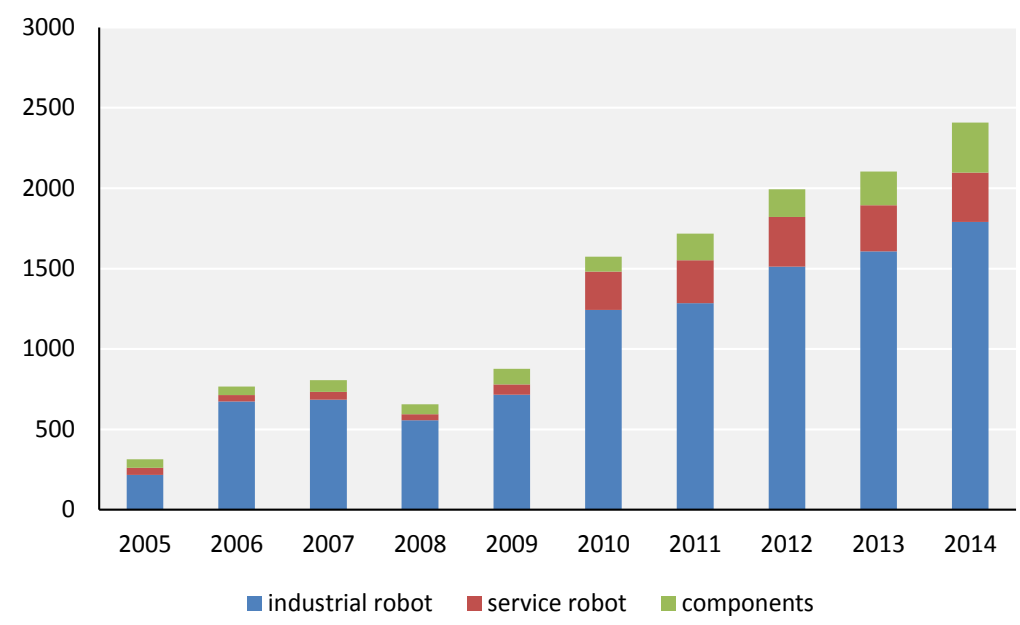

Source: KIRIA 
Japan also considers robotics as a key factor in future economic success, and the government has provided support for a new industrial revolution. In 2014, the Japanese government announced the "Japan Revitalization Strategy" to tackle social challenges such as the declining birth rate and shrinking population of productive age. New robot technologies and increased robot adoption are viewed as a way to help solve the labour shortage problem and increase productivity in manufacturing and the medical service sector. A "New Robot Strategy" was launched in 2015, which included a 5-year action plan to expand robot usage in industries and support the Japanese robotics industry.

This robot strategy is based on three pillars: 1) enhancement of Japanese robot creation ability, so as to make Japan a global robot innovation hub; 2) utilisation and dissemination of robots across the Japan to achieve a society with the highest level of robot utilisation in the world; and 3) standardisation of Japan's robot technology globally, and ensuring the security of data and the telecommunication network. The plan aims to use robotics in five key areas: manufacturing, service, nursing and medical care, infrastructure and disaster preparedness, agriculture. To accomplish the robot strategy, the Robot Revolution Initiatives Council was created in May 2015 and cooperation with Germany was referred to explicitly in the strategy.

In addition, the $5^{\text {th }}$ Science and Technology Basic Plan aims to promote R\&D for a "Super Smart Society", while the first Artificial Intelligence Research Centre was established in 2015 (in the meantime, Japan counts 3 centres of artificial intelligence). Recognising artificial intelligence as a critical technology, the Advanced Integrated Intelligence Platform Project was launched focusing on artificial intelligence, the Internet of Things, big data and cyber security.

In the United States, "A Roadmap for U.S. Robotics, From Internet to Robotics" report was released in November 2016. This roadmap updated the 2009 version that explored robotics as a key economic enabler in the areas of manufacturing, healthcare and the service industry. The 2016 roadmap expands the coverage significantly and includes explicitly areas as public safety, earth science and workforce development. In addition, the 2016 Roadmap also addresses concerns about possible job losses to automation. The new Roadmap calls for an adequate policy framework to allow the United States to be at the forefront of the design and deployment of new technologies without neglecting the risk of safety for people in their daily lives.

Along with the new Roadmap for U.S. robotics, the National Science Foundation (NSF) released the National Robotics Initiative 2.0 (NRI 2.0), i.e. the revision of the National Robotics Initiative (NRI) of 2011. The 2011 NRI was designed to support fundamental research, development and use of robotics in the United States, thereby focusing on the technologies that work with humans. The Initiative plans a USD 50 million research budget to develop co-robots (i.e. robots that work cooperatively with humans) as part of the Advanced Manufacturing Partnership Programme. In addition, research funding (USD 40-50 million) is provided for the next generation of robots, while a 4 billion USD plan supports the development of self-driving cars. The NRI 2.0 also discusses the need to include robotics into educational curricula and to increase the robotics.

One important motivation for these new versions of the Robotics Roadmap and NRI2.0 is the strategic importance of robotics for the future of US manufacturing. Robotics is considered as a key transformative technology that will revolutionise manufacturing. The Roadmap states that the effective use of robotics will increase US jobs, improve the quality of these jobs and enhance US competitiveness on global markets. The new Roadmap expects dramatic advances in robotics and automation technologies will be critical to the next generation of high value products. 
Europe has acquired a strong position in robotics and several policy measures are put in place to promote the research, development and investment in robots. The European Commission announced SPARC in 2014 which is a public-private partnership between the Commission, academia and business for the development of civilian robotics. Investments are expected to reach USD 2.8 billion. In addition, national initiatives across a large number of countries foresee in support of research and investments in robotics. In Germany for example, robots occupy an important position in the initiative Industry 4.0 which is backed by government, academia and business. A budget of more than EUR 350 million is foreseen to apply robotics, artificial intelligence, and the Internet of Things to advanced manufacturing. Similar initiatives exist in Italy (Factory of the Future), France (Factory of the Future, including the provision of loans to robotics SMEs and Robolution Capital, a venture capital fund to service robotics) and the United Kingdom (High Value Manufacturing; in addition, robotics and autonomous systems are identified as one of the Eight Great Technologies) to name a few.

As mentioned before, governments in a number of emerging economies have been aggressively supporting the research, development and usage of robotics. China has been a late entrant into the industrial robot market: between the 1970s and 2000, China's production and use of industrial robot was quite small. But in 2013 China became the largest market for industrial robots and the buyer of $27 \%$ of the world's industrial robots. The Chinese government recently announced its objective of raising its robot density $300 \%$ by 2020 , as it has identified robotics as a key success factor for the future of the Chinese economy and manufacturing industries. In its 10-year Action Plan "Made in China 2025" to transform China from a manufacturing-driven to an innovation-driven economy, robotics was identified as one of the 10 key sector areas for digitalisation and intelligent manufacturing. ${ }^{22}$ The broad goal of this plan is to upgrade Chinese manufacturing making it more efficient and move up the global value chain. The plan identifies the goal of raising domestic content of core components and materials to $50 \%$ by 2020 and $70 \%$ by 2025 .

The Chinese government implemented policy measures to support the development of a robot industry in China and the usage of industrial robots in Chinese manufacturing industries (chemicals, automotive, electronics, machinery, etc.). During the $10^{\text {th }}$ Five Year Plan (FYP) (20012005) and the $11^{\text {th }}$ FYP (2006-10) China has experienced the initial industrialisation stage of applying and incorporating industrial robots. Under these two consecutive plans, China has made progress on key technologies and got closer to international standards in robotics. But since 2011 the Chinese government has openly supported industrial robotics as an important factor to upgrade and transform China's manufacturing sector. The $12^{\text {th }}$ FYP (2011-15) stated that China was overly dependent on imports for high-end equipment and key components and called for developing technologies including robotics, sensors and controllers. The "Guideline on Promoting the Development of the Industrial Robot Industry" which was announced in 2013, identified the weakness in China's industrial robotics particularly China's dependency on imports for key components and the weak competitiveness of China's own brands of industrial robots (Ray et al., 2016).

The $13^{\text {th }}$ FYP (2016-20) includes the New Robotic Technology Roadmap with rising budgets for R\&D on robotics. The Robotics Industry Development Plan (2016-2020) released in April 2016 states that China is overly dependent on imports for key components, including high-precision reducers, servomotors and controllers. It calls for the production of 100000 industrial robots annually, with a robot density of 150 robots per 10000 employees. In addition, the Chinese government supports the development of 6 major robotics zones across the country, based in and around large economic areas (Beijing, Shanghai, Guangzhou, Chengdu, etc.). These plans and larger budgets are complemented by policy measures to support the education in robotics (academia, secondary schools but also vocational training) and actions to popularise the science of robotics and arouse public interest, especially with younger people. 
But also smaller emerging economies are promoting the investment and usage of robots. Chinese Taipei has implemented extensive government-industry-academia collaboration in order to develop its robotics industry. The government has heavily sponsored R\&D to develop robotics technologies as part of its Intelligent Robot Industry Development Strategy (2005) and Intelligent Robot Industry Development Acceleration Strategy (2007). To support robot usage in manufacturing industries, the Ministry of Economic Affairs has implemented "Productivity 4.0" and a number of international investors have been attracted to bring advanced manufacturing technologies to Chinese Taipei.

Policymakers in Thailand have also been encouraging the use of advanced technologies, acknowledging the fact that higher automation will determine the country's competitiveness in the future. "Thailand 4.0" has been launched identifying a future based on high-value production enabled by connectivity, data and high levels of automation. Although the market for robotics is currently still too small in Thailand to develop an indigenous robotics industry, the government aims to build its own robotics industry, and has rolled out incentives to try and stimulate investment in robots. Recently, a robotics development plan was announced to enhance a 200-billion-baht (USD 6 billion) investment scheme for the industry over the next five years. The measures are aimed at encouraging the manufacturing and service sectors to increase their productivity through the use of robotics and automation systems. Under the Super Cluster policy, investments in targeted industries - including automation and robotics - attracts an eight-year corporate income tax holiday, followed by a five-year $50 \%$ corporate income tax relief after that. There is also import duty exemption on machinery and raw materials.

\subsection{Conclusion and policy implications}

In contrast with such ambitious government policies implemented across countries, the previous analyses in this paper have reported to date rather limited impacts of robotics on the location of production within GVCs. In line with theory of how robotics will change production, the most important finding is the negative effect that robotics may have on the offshoring of activities from developed economies - i.e. robotics seem to decrease the need for relocating activities away from developed economies. This suggests as discussed further below that the rate of GVC expansion may be slower than in the past. But while robotics may thus keep production activities in developed economies, these same investments in robots do not seem strong or large enough to bring back activities that have been offshored in the past. In addition, robotics do not seem to be a major factor in attracting international investment, as no robotics effect is found on the international reallocation of resources within MNEs. Lastly, some preliminary effects of robotics are observed on GVC participation and GVC upgrading, particularly in developed economies.

Of course, the effects of robotics are expected to be much broader than on the location of production and GVC activities. It is clear that the different government measures are motivated by a large number of different objectives (which will be addressed in other OECD work). Furthermore, there are a number of reasons that may help explain the rather limited evidence found in this paper. First and foremost, it may be too premature to observe the potentially disruptive effects of robotics on the location of production. Investments in robots have grown significantly but only rather recently, and it can be expected that potential impacts will take some to materialise. ${ }^{23}$ This is particularly the case in emerging economies. If a robotics revolution is about to happen like some are arguing, one thing this paper calls for is the need for further and follow-up research in the coming years.

Second, while information on robotics has become increasingly available across industries and countries, including emerging economies, it should be taken into account that the available data only include information on the number (i.e. a count) of robots. Regretfully, no information is 
available on the size, and especially the growing quality of robots - one can easily assume that new vintages of robot investments have a higher performance - but this is not reflected in the data.

Third, robots are only one part of the wider digital revolution that is currently taking place. Other developments including the Internet of Things, artificial intelligence, etc. will additionally contribute to the digital revolution and consequently, it can be expected that companies will need to invest in complementary assets to fully benefit optimally from their investment in robotics. The data in this paper do not include information on these other components of the digitalisation of manufacturing, which may mean that the effects of robots are somewhat underestimated.

The negative effect of robotics on offshoring that is found in this paper, seems to be in line with the distinction made by Baldwin (2016) who argued about the differential effects of respectively communication and information technologies on the international fragmentation. The rapid progress in communication technologies has been one factor behind the rapid growth of GVCs in the past, as these technologies allow for the monitoring and coordination of production activities across large distances. Information technologies, including robots investment, instead may curb the further international dispersion of activities and may make developed economies more attractive (again) for manufacturing activities. One reason is that information technologies reduce the share of labour costs in total production costs. The fact that an extra effect of robotics in labour intensive industries is observed seems to support this argument. A second reason is that information technologies allow companies to customise their products better and much faster, which is increasingly becoming important in a number of industries.

The effect of robotics on offshoring in developed economies, based on historical data, also supports the results of De Backer and Flaig (2017), who simulated the future of GVCs based on a number of scenarios for the future. They reported that one specific scenario, namely the rapid progress in information technologies including robotics, will increase the attractiveness of OECD economies for manufacturing activities. This would be reflected in a decreased sourcing of intermediates from abroad, lower levels of offshoring and a stronger export position of OECD manufacturing in global markets.

The evidence in this paper albeit preliminary - and the need for follow-up analysis using more recent data cannot be emphasised enough - seems to indicate that robotics may become an important source of knowledge based capital. Previous OECD work has shown the importance of knowledge-based capital for productivity, competitiveness and long-term economic growth of countries. Most OECD countries see digital production as a new source of competitiveness in restoring their position in manufacturing industries. This is reflected in the growing number of policy measures that several OECD countries have implemented or are in the process of implementing.

Faced with these economic challenges, governments in emerging economies have also identified robotics as a key determinant of their future economic success. The growth model of emerging economies largely based on combining high-end technology with low labour costs will come under increasing pressure if developed economies increasingly automate their manufacturing and are successful in keeping/attracting production activities at home. In a number of emerging economies, labour costs have been rising quickly which makes the option of automation and larger robot usage at home or abroad - increasingly attractive, especially for companies who have offshored activities to these countries in search of low wages. In addition to compensating for rising labour $\operatorname{costs}^{24}$, robotics investments in emerging economies will also help them in upgrading their activities in terms of product quality, GVC positioning, etc. 
The likely outcome will be different across industries and countries. Countries with a strong export position in the automotive industry have a lot at stake since the car industry is gradually shifting to fully automated production. Other industries are "less automatable" and countries specialising in these industries may thus have some shelter from these developments in the near future. However, as robotics are getting cheaper and becoming more performant also in the number of activities they can be applied to, it can be expected that the so-called inflection point for investment in robots (BCG estimates this inflection point to be reached when using robots becomes $15 \%$ cheaper per hour than employing) will come closer in a growing number of industries and countries.

This process of growing automation, in developed as well as emerging economies, may further stimulate the process of premature de-industrialisation that has been observed recently in a number of economies. While the traditional model of economic development involves a shift from agriculture to manufacturing to services, Rodrik (2015) reported that a number of emerging economies are de-industrialising quicker than expected. The fact that automation - in developed economies but increasingly also in emerging economies - may increasingly replace low-cost jobs may mean that manufacturing will not be able to offer large numbers of jobs for the large labour supply in these countries. 


\section{NOTES}

1. Foxconn, the Chinese Taipei based multinational electronics contract manufacturing company - most known for assembling Apple products, is looking into deploying over 1 million robots in its business in the coming years (OECD, 2015).

2. The current systems of robotics replace primarily the 'routine' activities of lower skilled labour, while higher skilled labour is (still) needed to handle, monitor and if necessary to intervene, the machines. Future robots will more autonomous and self-learning, potentially diminishing their complementarity with higher skilled labour.

3. De Backer et al. (2016) reported that the aggregate evidence on reshoring is until now rather limited which stands somewhat in contrast to the anecdotal and survey evidence on this new phenomenon. Also the recent Eurofound report “European Monitor of Reshoring Annual Report 2016” notes that reshoring is a relevant phenomenon in the EU, not decreasing in size but that further data and research are needed to confirm whether it is growing.

4. In fact the IFR data exists from up to 2016, which we use for the descriptive analysis. However for the empirical analysis, data limitations with the GVC variables mean that the time period here is limited to 2000-14.

5. Note: an industrial robot refers to "an automatically controlled, reprogrammable, multipurpose manipulator programmable in three or more axes, which can be fixed in place or mobile for use in industrial automation applications” (IFR, 2016).

6. This does not appear to be a large assumption since differences in robot use between sectors over time is relatively consistent amongst the countries where complete information is available.

7. T1012: food, beverage and Tabaco, T1922: petroleum products, chemicals, rubber and plastics, T242528: basic metals and machinery, T2627: computers and electrical machinery, T2930: motor vehicle and transport, T3133: other manufacturing and recycling, Other: to wood, paper and publishing non-metallic minerals and education and research.

8. Nevertheless, rising wages have to be considered in combination with rising productivity. Further on, activities may be offshored from economies with rising wage costs to other emerging economies where wages are much lower and not rapidly increasing (for example from China to Cambodia)

9. Feenstra and Hanson called this measure an indicator of 'outsourcing' although the indicator actually measures offshoring since it is defined as companies’ purchases of intermediate goods and services excluding energy intermediate inputs - from foreign providers (at arms-length and from foreign affiliates).

10 . The indicator has been calculated on the basis of WIOD data which end in 2014. In addition, a number of control variables such as labour intensity, demand, and absorptive capacity (measured by patent stock) are included. These data are sourced from UNIDO, WIOD and PATSTAT databases 
respectively. After merging these datasets with the statistics on robotics, the sample includes roughly 40 countries over the period 2000-14.

11. The group of developed economies consists of the "high-income economies" identified by the World Bank. A high-income economy is defined by the World Bank as a country with a gross national income per capita of USD12 236 or more in 2016.

12. The effects of robots on offshoring - in developed as well as emerging economies - take into account a number of other variables expected to impact the growth offshoring - e.g. growth in domestic demand, labour intensity, patent stock (level as well as growth) as an indication of the innovative character of industries. In addition, fixed effects on the year level and country*industry level are included in the regressions.

13. In addition, the period 2010-14 concerns the years directly after the financial/economic crisis of $2008 / 2009$, eliminating the potential effects on offshoring of the large changes in the world economy during 2008-2009. Robustness analysis with more recent periods 2009-14 and 2011-14 did not change the results reported above.

14. In order to check for this, the evolution of productive resources in affiliates abroad is split out in a positive and negative component (i.e. a negative coefficient for the negative growth abroad lends support for reshoring); see for more details De Backer et al. (2016).

15. The robotics variable is constructed as the growth in robots stock of the home country relative to the average of the growth in robots stock in the countries where the group has affiliates; this in order to take into account the different geographical spread of MNE groups. Of course, this is only an indirect and rough proxy of the potential effect of robotics since the robotics is constructed on the countryindustry level while the allocation of resources is based on firm-level data.

16. The robotics variable is now constructed as the growth in the robots stock of the affiliate country relative to the average of the growth in robots stock in the countries where the group has affiliates; as in the previous analysis on backshoring, this is in order to take into account the different geographical spread of MNE groups. Again, this is only an indirect and rough proxy of the potential effect of robotics (country-industry level of robotics versus firm-level performance).

17. The coverage of the ORBIS database is more limited for emerging economies, hence the analysis for this group of countries can be expected to be less representative.

18. Change in the backward participation is calculated as the change in the share of imported inputs in exports while change in forward participation is the change in the share of exported goods and services used as imported inputs to produce other economies' exports (see OECD, 2013). GVC upgrading is calculated as the change in domestic value added as a share of exports. As GVC upgrading can happen along different trajectories, this measure provides only a rough indication of GVC upgrading (OECD, 2013).

19. As GVC integration and upgrading concern structural characteristics of industries and countries - and thus may take some time before effective changes are observed, changes over 2 and 3 years are also included. Estimations are the result of a reduced model including the robot variable and different fixed effects (year and country*industry).

20. In several countries, governments are debating how to regulate the emerging and important sector of robotics, including primarily laws on worker safety, cyber security, liability for autonomous and semiautonomous systems, and potential job displacement. 
21. Delegates are invited to provide more information about specific policies in their countries to be included in the next version of this paper.

22. Others include new advanced information technology, automated machine tools, aerospace and aeronautical equipment, maritime equipment and high-tech shipping.

23. The fact that the analyses in this paper could only include data up to 2014, has not helped to identify the effects in most recent years.

24. BCG has developed a number of scenarios extrapolating the different investments paths in robots across countries and their effect on labour costs. While tentative, this analysis shows the significant impacts robotics may have on labour costs (in particular their share of production costs) and hence the competitiveness of countries on international markets. 


\section{REFERENCES}

Acemoglu, D. and P. Restrepo (2017), "Robots and Jobs: Evidence from US Labor Markets”. NBER Working Paper No. 23285

Agapakis, J. et al. (1990), "Vision-aided Robotic Welding: an Approach and a Flexible Implementation”. The International Journal of Robotics Research, Vol 9/5: pp. 17-34.

Alix Partners (2017), “Homeward Bound: Nearshoring Continues, Labour Becomes a Limiting Factor, and Automation Takes Root", https://emarketing.alixpartners.com/rs/emsimages/2017/pubs/EI/AP Strategic Manufacturing Sourcing Homeward Bound Jan 2017.pdf

Amiti, M. and A.K. Khandelwal (2013), "Import Competition and Quality Upgrading”. The Review of Economics and Statistics Vol 95/2: pp. 476-490.

Argote, L. and P. Goodman (1985), “The Organizational Implications of Robotics”, Pittsburgh

Baldwin, R. (2016), “The Great Convergence: Information Technology and the New Globalisation”, Harvard University Press

Bogue, R. (2013), "Robotic Vision Boosts Automotive Industry Quality and Productivity”, Industrial Robot: An International Journal, Vol 40/5: pp. 415-419.

The Boston Consulting Group (2015), “The Robotics Revolution, the Next Great Leap in Manufacturing”, Manufacturing, Innovation Growth, https://www.bcgperspectives.com/content/articles/lean-manufacturing-innovation-roboticsrevolution-next-great-leap-manufacturing/

Brynjolfsson, B. and A. McAfee (2014), “The Second Machine Age: Work, Progress and Prosperity in a Time of Brilliant Technologies”. W.W. Norton and Company.

Christensen, H. (2016), “A Roadmap for US Robotics: From Internet to Robotics”.

Clifford, S. (2013), “U.S. Textile Plants Return, With Floors Largely Empty of People”. The New York Times.

Dachs, B. and C. Zanker (2015), "Backshoring of Production Activities in European Manufacturing”, MPRA Paper No. 63868 
De Backer, K., C. Menon, I. Desnoyers-James and L. Moussiegt (2016), "Reshoring: Myth or Reality?”, OECD Science, Technology and Industry Policy Papers, No. 27, OECD Publishing, Paris. http://dx.doi.org/10.1787/5jm56frbm38s-en

De Backer, K. and D. Flaig (2017), "The Future of Global Value Chains: Business as usual or "a new normal”?", OECD Science, Technology and Industry Policy Papers, No. 41, OECD Publishing, Paris. http://dx.doi.org/10.1787/d8da8760-en

Engineering and Physical Science Research Council. (2016), "Governments Drive the Robot Revolution”, http://hamlyn.doc.ic.ac.uk/uk-ras/news/investing-robotics

Eurofound (2016), "ERM Annual Report 2016: Globalisation Slowdown? Recent Evidence of Offshoring and Reshoring in Europe”, Brussels, https://www.eurofound.europa.eu/sites/default/files/ef_publication/field_ef_document/ef1652en .pdf

Feenstra, R. and G. Hanson, (1996), “Globalization, Outsourcing, and Wage Inequality”, The American Economic Review, Vol 86/2: pp. 240-245.

Feenstra, R.C. and J. Romalis (2014), “International Prices and Endogenous Quality”. Quarterly Journal of Economics, Vol 129/2: pp. 477-527.

Feng, B, (2016), “Elon Musk: Tesla’s Model 3 Factory Could Look like an Alien War”. Washington Post.

Ford, M, (2009), "The Lights in the Tunnel: Automation, Accelerating Technology and the Economy of the Future". Acculant Publishing.

Frey, C. and M. Osborne (2017), "The Future of Employment: How Susceptible are Jobs to Computerisation?”, Technological Forecasting and Social Change, Vol 114 (2017): pp. 254280.

Gates, D. (2013), "Painting Robots Speed Production of Boeing 777s". USA TODAY. https://www.usatoday.com/story/todayinthesky/2013/06/03/painting-robots-speed-productionof-boeing-777s/2384009/

Graetz, G. and G. Michaels (2015), “Robots at Work”, CEP Discussion Paper No. 1335.

Gunasekaran, S. (1996), “Computer Vision Technology for Food Quality Assurance”. Trends in Food Science \& Technology, Vol 7/8: pp. 245-256.

International Federation of Robotics (IFR) (2012), "History of Industrial Robots: From the first installation until today”. IFR Publishing, Frankfurt

International Federation of Robotics (IFR) (2016), “World Robotics Report 2016”, IFR Press Release. Frankfurt

International Federation of Robotics (IFR) (2016), “Wold Robotics: Industrial Robots”, IFR Publishing, Frankfurt 
International Federation of Robotics (IFR) (2017), “World Robotics Report 2017”, IFR Press Release. Frankfurt

Korea Government (2014), “Second Master Plan for the Korea Intelligent Robot Industry, 2014 to 2018”, Coordination of all relative ministries, Seoul.

Korea Government (2009), “First Master Plan for Korea Intelligent Robot Industry, 2009 to 2013”, Coordination of all relative ministries, Seoul.

Larson, A. (2013), "Rethink's Baxter vs Universal Robots: Which Collaborative Robot is best for you? " Motion Controls Solutions.

Lee,. Byung-ki. (2017), “Evaluation of Korea Robot Industry and Policy Implication” KERI Brief.

Lewis, C. (2014), "Robots Are Starting to Make Offshoring Less Attractive”, Harvard Business Review.

Manufacturers' Monthly. (2016), “Thailand's Robotics Drive”, http://www.manmonthly.com.au/features/thailands-robotics-drive/

Markoff, J. (2012), “New Wave of Deft Robots Is Changing Global Industry”. The New York Times.

Michalos, G. et al. (2016), "Performance Assessment of Production Systems with Mobile Robots". Procedia CIRP, Research and Innovation in Manufacturing: Key Enabling Technologies for the Factories of the Future - Proceedings of the 48th CIRP Conference on Manufacturing Systems.

Michalos, G., S. Makris and G. Chryssolouris (2015), “The New Assembly System Paradigm”. International Journal of Computer Integrated Manufacturing, Vol 28, pp. 1252-1261.

Miller, M. (2013), “Bringing Back Jobs to the U.S. via the Robot”, CBS News.

Ministry of Trade, Industry and Energy. (2005), “Vision and Strategy for Korea Intelligent Robot Industry", Korea

Ministry of Trade, Industry and Energy and Korean Institute for Robot Industry Advancement. (20092015), "Research on the Actual Condition of the Robot Industry".

OECD (2017a), “Going Digital: Making the Transformation Work for Growth and Well-Being”, Document prepared for the MCM 2017 Meeting, OECD publishing, Paris https://www.oecd.org/mcm/documents/C-MIN-2017-4\%20EN.pdf

OECD (2017b), "Benefits and Challenges of Digitalising Production", Chapter 2 in The Next Production Revolution: Implications for Governments and Business, OECD publishing, Paris http://dx.doi.org/10.1787/9789264271036-6-en

OECD (2016a), "The Risk of Automation for Jobs in OECD Countries, A Comparative Analysis”, OECD Social, Employment and Migration Working Papers, No. 189, OECD Publishing, Paris http://dx.doi.org/10.1787/5jlz9h56dvq7-en

OECD (2016b), Determinants and Impact of Automation: an Analysis of Robots' Adoption in OECD countries, internal OECD document 
OECD (2015), “Data-Driven Innovation”. Paris: Organisation for Economic Co-operation and Development, OECD Publishing, Paris, http://dx.doi.org/10.1787/9789264229358-en

OECD (2013), “Interconnected Economies. Benefitting from Global Value Chains”, OECD Publishing, Paris. http://dx.doi.org/10.1787/9789264189560-en

Pricewaterhouse Coopers (2014), “The New Hire: How a New Generation of Robots is Transforming Manufacturing”. Delaware limited liability partnership.

Qiao, H., R. Li and P. Yin. (2015), "Robotics and Automation Activities in China”, IEEE Robotics and Automation Magazine, Vol 22/3: pp. 14-17.

Ray, J. Atha, K. Francis, E. Dependahl, C. Mulvenon, J. Alderman, D. and Leigh Ann Ragland-Luce. (2016). "China's Industrial and Military Robotics Development" Center for Intelligence Research and Analysis.

Robot Revolution Realization Council (2015), “Japan’s Robot Strategy: Vision, Strategy, Action Plan”

Rodrik, D. (2015), “Premature Deindustrialization,” NBER Working Paper No. 20935, February 2015.

Simonite, T. (2016), “This Truck is the Size of a House and Doesn’t Have a Driver”, MIT Technology Review.

The Economist (2017), “Adidas’s High-Tech Factory Brings Production Back to Germany”, The Economist.

Theparat, C., (2017). "Development Plan for Robotics Gets Nod,” Bangkok Post, http://www.bangkokpost.com/business/news/1315391/development-plan-for-robotics-gets-nod

UNCTAD (2016), “Robots and Industrialization in Developing Countries”. UNCTAD Policy Brief No. 50

UNCTAD (2014), “World Investment Report”, 2014. United Nations, New York and Geneva.

U.S. Chamber of Commerce (2017), “Made in China 2025: Global Ambitions Built on Local Protections"

Waters, R. and T. Bradshaw (2016), “Rise of the Robots is Sparking an Investment Boom”, Financial Times. 


\section{ANNEX A: EMPIRICAL STRATEGIES AND VARIABLE DESCRIPTIONS}

\section{A1.1. Robot stock and offshoring}

1. The model used to estimate the effects of robot stock on offshoring is illustrated in Equation (1.0):

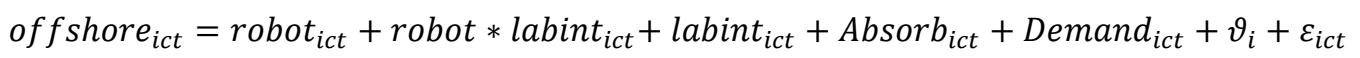

offshore reflects the annual growth in offshoring across sector $i$ in country $c$ in time $t .^{\mathrm{xxv}}$ Offshoring is defined as the share of imported intermediate goods and services - excluding energy intermediate inputs, over the sum of intermediate goods and services- excluding energy intermediate inputs (Feenstra and Hanson 1996). Our variables of interest robot and robot $*$ labint capture the effects of the growth in robot stock and robots conditional on labour intensity on offshoring. We also include a number of control variables believed to be related to offshoring including growth in absorptive capacity (measured by patent stock) Absorb, and growth in Demand of the country and sector over time. Country*sector and year fixed effects are also included to control for economy industry as well as year variation over time.

\section{A1.2. Robot stock and backshoring}

In Equation (2.0) the employment or fixed assets growth rate at home of company i part of group $\mathrm{g}$ in year $\mathrm{t}$ is regressed over the aggregate growth rate of the same variable of affiliates abroad The growth abroad variable $a b d$ is split in two variables $a b d_{-} p$ and $\_n$, depending on whether it takes a positive or negative value, respectively. Doing so allows the change in growth rate at home to be different in sign and magnitude depending on whether affiliates abroad are expanding or contracting, respectively.

If there is backshoring, the relationship is expected to be negative - i.e., an increase in employment or investment at home is associated with a decrease in employment or investments abroad. However, a negative association may actually be also a symptom of offshoring, i.e., a decrease in employment or investment at home is associated with an increase in employment or investments abroad. Therefore in this kind of analysis it is important to distinguish positive from negative changes in employment and fixed capital assets.

Interacting the growth abroad variables with relative robot stock of the group over the average affiliate $\left(a b d_{p} *\right.$ robot and $a b d_{n} *$ robot) allows us to assess the extent to which robots are contributing to the backshoring or resources within the MNE. If robotics contributes to backshoring one should expect to find a negative coefficient of for the $a b d_{-} n_{g t} *$ robot variable. In order to examine whether robot use in the home country is related to backshoring, our robot measure represents the log different in the robot stock of the country and sector of the headquarters over the average log difference of the robot stock for the sectors and countries of the affiliates abroad.

$$
h o m e_{i g t}=a b d \_p_{i g t}+a b d_{-} n_{i g t}+a b d \_p_{i g t} * \text { robot }+a b d \_n_{i g t} * \text { robot }+g r p_{-} a v e_{i g t}+\delta_{i g t}+\varepsilon_{i t}
$$




\section{A1.3. Robot stock and reallocation}

Equation (3.0) uses the same firm-level information on fixed capital and employment as in Equation (2.0) for the dependent variable but now at the level of individual MNE affiliates signified by aff_factor. This is regressed on robot stock of the affiliate country and sector. Control variables are also added, including growth in demand within the country $c$ sector $s$ and year $t$ of the affiliate, the average growth of the group (either employment or fixed assets) signified as factor and sector*year country*year fixed effects represented by $\vartheta$.

$$
a f f_{-} \text {factor }_{\text {asct }}=\text { robot }_{c s t}+\text { demand }_{\text {sct }}+\text { factor }_{\text {gsct }}+\vartheta_{t}+\varepsilon_{\text {asct }}
$$

\section{A1.4. Robot stock, GVC upgrading, comparative advantage and participation}

Equation 4.0 is a reduced form model used to estimate the effects of growth in robot stock on GVC performance, including forward and backward participation, GVC upgrading and relative comparative advantage. $g c v_{i c t}$ refers to our growth measure of GVC performance at country $c$, in sector $s$ at time $t$. Our variable of interest robot signifies the growth of robot stock within that particular country, sector and year. In order to control for variation between countries and sectors and potential temporal shocks we include country $*$ isic and year fixed effects.

$$
g v c_{i c t}=\text { robot }_{i c t}+\text { country } * \text { isic }+ \text { year }+\varepsilon_{i c t}
$$

The change in the backward participation is calculated as the change in the share of imported inputs in exports, while change in forward participation is the change in the share of exported goods and services used as imported inputs to produce other economies' exports (see OECD, 2013). GVC upgrading is calculated as the change in domestic value added as a share of exports. Finally relative comparative advantage is the value of exports of sector $i$ in country $c$ over of the sum of exports of country $c$ in time $t$ over the value of exports in sector $i$ for the world $w$ over the sum of exports for the world in time $t$ (See Equation 5.0).

$$
\frac{\frac{x_{i c}}{\sum x_{c t}}}{\frac{x_{i w}}{\sum x_{w t}}}
$$

xxv. Growth is calculated as the log difference of the variable over the specified period. 


\section{ANNEX B}

Table B.1. Effects of growth in robotics on imports over demand

\begin{tabular}{|c|c|c|c|c|}
\hline & \multicolumn{2}{|c|}{ HDC } & \multicolumn{2}{|c|}{ LDC } \\
\hline Dependent var: Offshoring (annual growth) & $2000-2014$ & 2010-2014 & $2000-2014$ & 2010-2014 \\
\hline \multirow[t]{2}{*}{ Robot stock (annual growth) } & 0.030 & 0.026 & -0.036 & -0.058 \\
\hline & $(0.05)$ & $(0.08)$ & $(0.03)$ & $(0.08)$ \\
\hline \multirow[t]{2}{*}{ Robot stock *Labour Intensity } & 0.015 & 0.013 & -0.010 & -0.029 \\
\hline & $(0.02)$ & $(0.04)$ & $(0.01)$ & $(0.03)$ \\
\hline \multirow[t]{2}{*}{ Labour Intensity } & $-0.075^{\star \star \star}$ & $-0.145^{\star \star}$ & -0.007 & -0.067 \\
\hline & $(0.02)$ & $(0.06)$ & $(0.01)$ & $(0.09)$ \\
\hline \multicolumn{5}{|l|}{ Control Variables } \\
\hline Year & $\checkmark$ & $\checkmark$ & $\checkmark$ & $\checkmark$ \\
\hline Country*Industry & $\checkmark$ & $\checkmark$ & $\checkmark$ & $\checkmark$ \\
\hline R-squared & 0.591 & 0.678 & 0.545 & 0.633 \\
\hline Observations & 5398 & 1931 & 1799 & 611 \\
\hline
\end{tabular}

